\title{
HUMAN CAPITAL FORMATION DURING THE FIRST INDUSTRIAL REVOLUTION: EVIDENCE FROM THE USE OF STEAM ENGINES
}

\author{
Alexandra de Pleijt \\ University of Oxford, Utrecht University, \\ and Queen's University Belfast \\ Jacob Weisdorf \\ University of Southern Denmark
}

\author{
Alessandro Nuvolari \\ Sant'Anna School of Advanced Studies
}

\begin{abstract}
We examine the effect of technical change on human capital formation during England's Industrial Revolution. Using the number of steam engines installed by 1800 as a synthetic indicator of technological change and occupational statistics to measure working skills (using HISCLASS), we establish a positive correlation between the use of steam engines and the share of skilled workers at the county level. We use exogenous variation in carboniferous rock strata (containing coal to fuel the engines) to show that the effect was causal. While technological change stimulated the formation of working skills, it had an overall negative effect on the formation of primary education, captured by literacy and school enrolment rates. It also led to higher gender inequality in literacy. (JEL: J82, N33, O14, O33)
\end{abstract}

\section{Introduction}

Has technical progress historically been skill-saving or skill-demanding? The consensus is that technical change after the late 19th century has favoured more

The editor in charge of this paper was Claudio Michelacci.

Acknowledgments: We thank the conference audience at the 17th and 18th World Economic History Congresses the CAGE Workshop on Economic Geography and History, the 2016 Economic History Association Conference, as well as the seminar participants at Rutgers University, University Paris Dauphine, Utrecht University, University of Oxford, the University of Tubingen, and the London School of Economics for helpful comments and suggestions. We are grateful to Leigh Shaw-Taylor for sharing the occupational data of the Cambridge Group; to Chris Minns and Patrick Wallis for sharing the rolls of the Commissioners of Stamps; to Helen Aitchison for proofreading; and to Sascha Becker, Dan Bogart, Michael Bordo, Steve Boardberry, Greg Clark, James Fenske, Alan Fernihough, Oded Galor, Alexander Field, Jean Lacroix, Alexandra Lopez-Cermeno, Ralf Meisenzahl, Joel Mokyr, Jaime Reis, Natacha PostelVinay, Eric Schneider, Jan Luiten van Zanden, and Nico Voigtländer for help with data and data preparation, as well as various useful suggestions. Alexandra de Pleijt has benefitted from funding made available by the Netherlands Organisation for Scientific Research (NWO) project number 446-16-014. Weisdorf is a CEPR Research Fellow.

E-mail: sandradepleijt@gmail.com (de Pleijt); alessandro.nuvolari@santannapisa.it (Nuvolari); jacobw@sam.sdu.dk (Weisdorf) 
skilled workers (e.g., Griliches 1969; Goldin and Katz 1998; Acemoglu 2002). There is less agreement, however, as one moves further back into the 19th century (e.g., Katz and Margo 2014). Recent contributions in growth theory have argued for a positive effect of technical change on human capital formation during the transition towards "modern economic growth" (e.g., Galor and Moav 2006; Galor 2011). But the conventional wisdom, based on evidence from the 19th-century United States, is that technical change was predominantly "de-skilling" as the factory system began to replace the artisanal workshop (Goldin and Sokoloff 1982; Atack et al. 2004, 2008). Turning to Europe, the notion of complementarity between technical change and working skills has received empirical support from 19th-century France (Franck and Galor 2017). The French evidence contrasts, however, with the traditional narrative about the effects of early industrialisation in England, where earlier work in line with the US evidence has argued that skill-displacement was the main outcome of technological change (e.g., Berg 1994). In particular, the classical years of England's Industrial Revolution have been characterised by stagnant rates of male literacy (e.g., Schofield 1973; Nicholas and Nicholas 1992; Mitch 1999); declining average years of secondary schooling (de Pleijt 2018); higher shares of unskilled workers (de Pleijt and Weisdorf 2017); and the absence of noteworthy variations of the skill premium (e.g., Clark 2005; Allen 2009; Van Zanden 2009). Combined with a long list of chronicles about machine-breaking riots, triggered by workers' fears that the new factories would render their skills redundant (Nuvolari 2002), the English case, at least prima facie, seems to provide support to the hypothesis that the shift from workshop to factory production reduced the demand for skilled workers. But the effect of technical change on human capital formation during the first Industrial Revolution has not been tested formally.

This study breaks new ground in three ways. First, previous work attempting to quantify the evolution of human capital in England during the Industrial Revolution has mainly focused on literacy and numeracy rates. However, though meticulously documented (Nicholas and Nicholas 1992; Mitch 1999; Baten et al. 2014), literacy and numeracy skills measure only very basic competencies. For example, the literacy rate assigns the same level of ability to a literate factory worker and a literate industrial engineer, with no distinction being made between these two very dissimilar occupations that require large differences in aptitude. Moreover, the fact that any literacy and numeracy skills obtained were not necessarily used productively, such as a factory worker's ability to read and write, makes the potential discrepancy between the acquisition of skills and the application of skills in production a relevant matter; and one that is difficult to address using information about basic competencies, such as literacy or numeracy, to measure human capital attainments.

In this study, thanks to early 19th-century occupational statistics provided by the Cambridge Group for the History of Population and Social Structure and documented in Shaw-Taylor et al. (2006), we are able for the first time to classify over 2.6 million English male workers according to the skill-content of their work. The categorisation of occupational titles by skill, which is done by employing a standardised work-classification system (HISCO-HISCLASS), allows us to translate the sampled 
occupational titles into four (already existing) categories of work: unskilled, lower-skilled, medium-skilled, and highly skilled work. This in turn enable us to quantify the county-specific shares of unskilled, lower-skilled, medium-skilled, and highly skilled workers and to explore the correlation between those shares and countyspecific technological change. The occupational data also enable us to identify the so-called "density in the upper tail of professional knowledge" and to examine whether or not the diffusion of new technology during the Industrial Revolution stimulated a growing class of highly skilled mechanical workers, as proposed in Mokyr (2005), Mokyr and Voth (2009), Feldman and van der Beek (2016), and Zeev et al. (2017). ${ }^{1}$ In addition to working skills derived from occupations, we also employ more conventional indicators of human capital formation, such as literacy and school enrolment rates.

Second, we employ the methodological approach proposed in Franck and Galor (2017) for historical France, taking it across the channel to England, that is, the cradle of the Industrial Revolution and the frontrunner in modern economic growth. Franck and Galor used regional variation in the diffusion of steam technology to show that more steam engines were associated with higher rates of literacy, more apprentices, more teachers, and more schools. Similar to Franck and Galor, we exploit county-level variation in the use of steam engines to investigate the effect of technological change on the formation of human capital, although here in the English case. The English steam dataset is an updated version, previously used in Nuvolari et al. (2011), of that originally presented in Kanefsky and Robey (1980). The dataset contains detailed information about all known steam engines built and installed in England between 1698 when the first steam-engine prototype was patented and 1800. These data represent the best quantitative appraisal of the early diffusion of steam power during England's Industrial Revolution (Nuvolari et al. 2011).

Finally, in order to establish whether or not any observed effects between technology and human capital were causal, and because steam engines run on coal, we use exogenous variation in the prevalence of carboniferous rock strata (Asch 2005) as an instrument for the number of steam engines per person installed in 1800. Coal is found in rock layers from the Carboniferous age, which were created more than 300 million years ago. During this era, large forests covered the areas that later formed the earth's coal layers. The coalfields that supplied the emerging industries during the early phases of the Industrial Revolution therefore appeared near to rock strata from the Carboniferous epoch. We use the fact that the share of carboniferous rock strata in a county is highly correlated with the number of steam engines per person installed by 1800 , but that the concentration of rock strata is independent of the county's pre-industrial indicators of development and human capital formation.

Our analysis shows that the use of steam technology was positively associated with working skills. More steam engines per person were linked to lower shares of unskilled workers and higher shares of lower- and medium-skilled workers. We

1. Meisenzahl and Mokyr (2012) and Squicciarini and Voigtländer (2015), conversely, have emphasized the role that highly skilled individuals played in fostering the Industrial Revolution. 
propose that these findings are more consistent with a farmwork-to-factory transition than with the traditional workshop-to-factory argument as put forth in earlier studies (e.g., Goldin and Katz 1998). We also establish that more engines per person were positively connected with higher shares of highly skilled mechanical workers, such as engineers, wrights, and machine makers, representing the "density in the upper tail of professional knowledge".

Our analyses also show that the use of steam technology was either negatively associated with or had no significant effect on primary education. More steam engines per person were linked to fewer primary schools per person; and, although a more intensive use of steam engines was not statistically associated with lower male literacy rates and school enrolment rates, counties with comparatively many steam engines per person had significantly lower rates of female literacy and significantly higher levels of gender inequality in literacy than less steam-intensive counties. The inconclusive effect of more steam on male literacy could, however, owe to the fact that working and schooling skills were positively correlated for higher- and medium-workers, but not for lower- and unskilled workers.

Using the prevalence of carboniferous rock strata as an instrument for the number of steam engines per person, we show that the effects are causal. For example, if a county with no steam technology had increased its number of engines per 1,000 persons to the level of Yorkshire West Riding, an important early industrial centre representing the 85 th percentile and with 0.44 engines per 1,000 persons, then it would have led to a 13 percentage-points decline in the share of unskilled workers (relative to a sample mean of $42 \%$ ). This in turn implies that one more steam engine would have led to some 295 fewer unskilled workers.

Regarding basic schooling, we find a statistically significant negative effect of steam technology on the number of primary schools per person and on female literacy rates. Increasing the number of steam engines per 1,000 persons from zero to the number in Yorkshire West Riding would have decreased the number of primary schools per 1,000 persons by $64 \%$ (relative to a sample mean of 0.47 schools per 1,000 of the population). We also observe that more steam engines increase gender equality in literacy. Growth in the use of steam engines from zero to the level in Yorkshire West Riding would have increased gender inequality in literacy by 11 percentage-points (relative to a sample mean of $18 \%$ ). These findings are robust to accounting for a wide range of confounding factors, including geographical characteristics and pre-industrial performances, as well as alternative mechanical powers, such as cotton-, wool-, and water mills. The findings are also robust to controlling for spatial autocorrelation and potential outliers.

The ambiguous effect of the Industrial Revolution on the formation of human capital supports the narrative that England's early industrialisation either harmed or had a neutral effect on primary education (e.g., Nicholas and Nicholas 1992; Berg 1994; Mitch 1999; de Pleijt 2018). But the observed effects also show that early industry stimulated the formation of formal working skills, particularly industryspecific ones, as pointed out in previous work (e.g., Mokyr 2005; Mokyr and Voth 2009; Feldman and van der Beek 2016; Zeev et al. 2017). The latter effects align 
with Unified Growth Theory, according to which technological progress during the Industrial Revolution prompted investment in human capital (Galor and Weil 2000; Galor 2011). The ambiguous nature of the findings further chimes with theoretical work by O'Rourke et al. (2013), which argues that early industrial technological progress could be simultaneously skill-saving and skill-demanding.

The remainder of our paper is organised as follows. Section 2 presents the steam data and the various indicators of human capital, as well as the confounding variables. Section 3 explains the identification strategy and presents the results of our OLS and IV regressions. Section 4 shows that the results are robust to wide range of confounding factors as well as to alternative regression models. Section 5 summarises the main findings.

\section{Data}

The key innovation of the Industrial Revolution, together with the manually driven spinning wheel, was the atmospheric steam engine. In 1845 Friedrich Engels noted that "The history of the proletariat in England begins in the second half of the last [i.e., 18th] century, with the inventions of the steam engine and of machinery for working cotton. These inventions gave rise, as is well known, to an Industrial Revolution, a revolution that altered civil society, one, the historical importance of which is only now beginning to be recognized" (Engels 1993, p. 15). Engels' concise account of the Industrial Revolution combines two major driving forces of industrialisation: the mechanisation of production, and the use of coal to replace man or animal power. Both forces, according to Sir Antony Wrigley, were decisive for Britain's escape from the constraints of an organic economy and its subsequent world economic leadership (Wrigley 2010, 2016).

The steam engine, being the first apparatus that efficiently converted heat energy to mechanical energy, quickly became the cornerstone of England's industry. Whereas the earlier use of water- and windmills were intrinsically tied to very specific geographical locations that provided these elements, steam engines could be used wherever coal could be found or easily transported. Steam engines, in Wrigley's words, therefore "came to be employed almost universally in industry as the most convenient, powerful and cheapest source of mechanical energy during the middle decades of the nineteenth century" (Wrigley 2016, p. 210). Throughout the 19th century, technical advancements linked to the use of steam power increasingly interacted with the developments of various machines, which was critical to the process of industrialisation (von Tunzelmann 1978; Allen 2009). In this sense, the steam engine stands out as the most significant technological advancement of the Industrial Revolution (Freeman and Louca 2001).

\subsection{The Main Explanatory Variable: Steam Engines per Person}

To examine the relationship between technological change and human capital formation during the first Industrial Revolution, we use cross-county variation in 


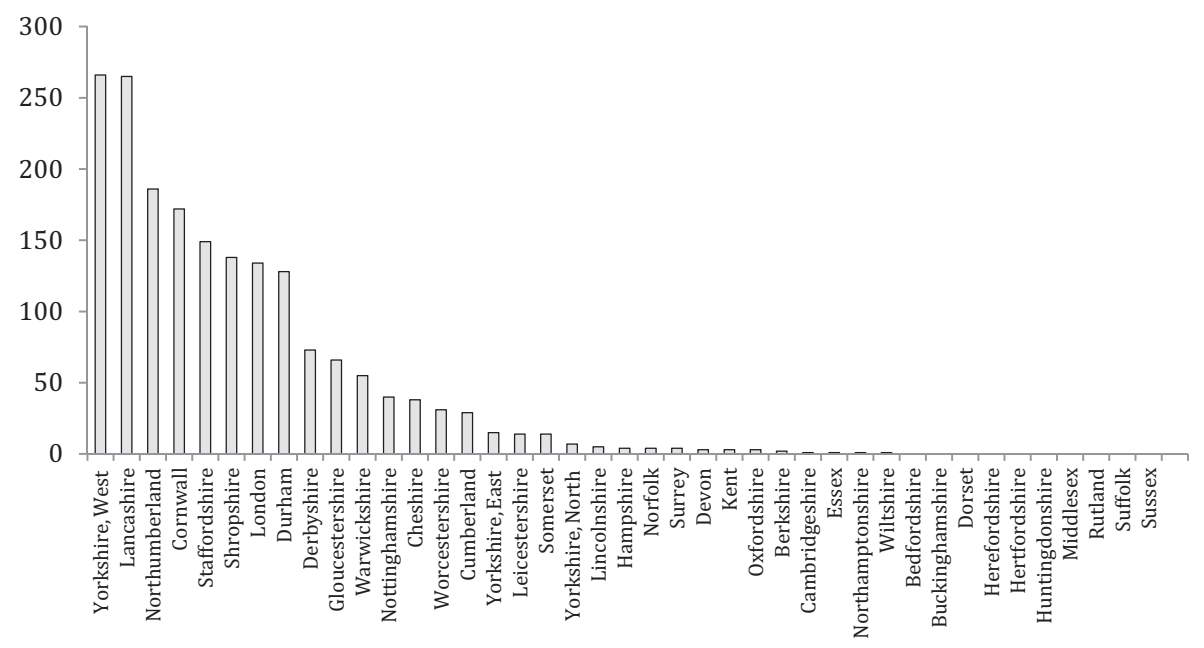

FIGURE 1. The distribution of steam engines built and installed by 1800 . Source: Nuvolari et al. (2011).

the number of steam engines per person built and installed by 1800 as a proxy for the implementation of new industrial technology. The steam engine data used in what follows is an updated version of the dataset originally constructed and published by Kanefsky and Robey (1980). The first steam engine included in the dataset is the famous so-called atmospheric engine, which was patented by Thomas Savery in 1698 and put to use for the first time in 1702 (Nuvolari et al. 2011). During the second half of the 18th century, steam engines were increasingly employed, especially in the most innovative and dynamic branches of the English economy, that is, the iron, mining and cotton industries. By 1800, a total of 2,207 steam engines had been built and installed across England.

The intensity in the use of steam power varied considerably across the English counties, as shown in Figures 1 and 2. Not surprisingly, steam engines were very common in England's industrial centres, including Lancashire and Yorkshire West Riding, each of which had over 250 engines installed by 1800 . On the other hand, counties that were dominated by agriculture during the classical years of the Industrial Revolution, such as Dorset and Sussex, had no steam engines installed at all.

Steam engines were initially used to help drain water from the mines, but from the $1740 \mathrm{~s}$ onwards steam technology was increasingly used in the two key "modernizing" sectors in the Crafts-Harley interpretation of the Industrial Revolution, that is, the production of textiles and metals (Crafts and Harley 2002). ${ }^{2}$ By 1800 , steam technology had also been adopted in the mechanisation of other dynamic branches of manufacturing, including large-scale brewing and paper-making factories (Von Tunzelmann 1978, 1986).

2. The share of steam engines used in manufacturing and other sectors by 1800 was much larger than that used in mining, Kanefsky and Robey (1980, p. 181). 


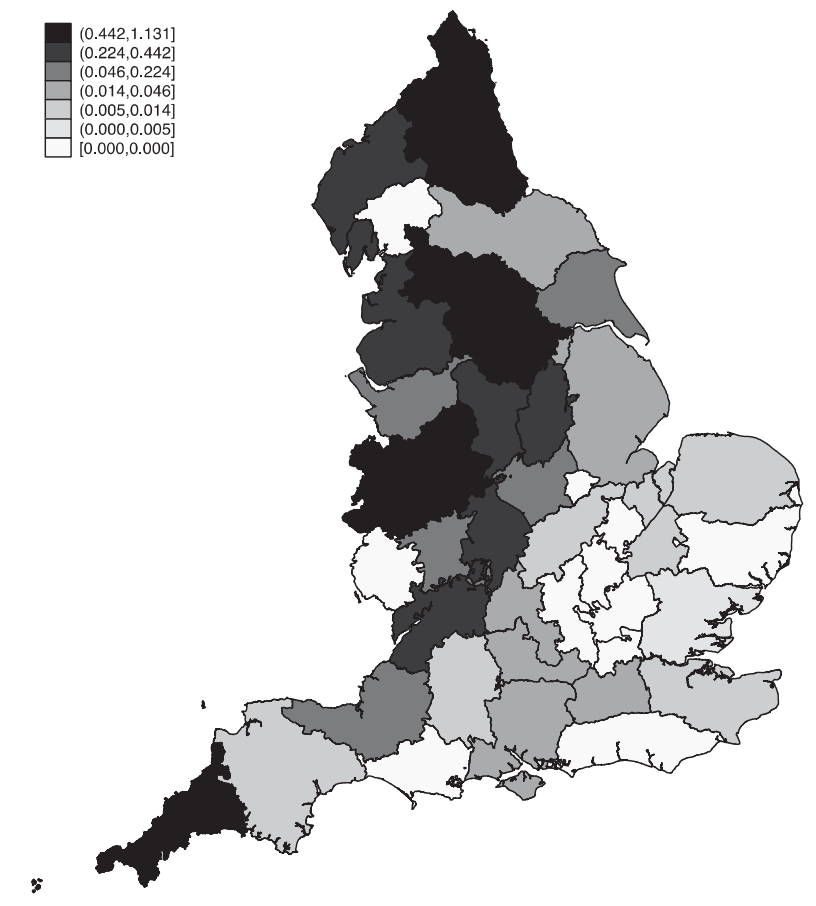

FIGURE 2. Steam engines per 1,000 people in 1800. A map containing the names of the counties is found in Appendix B. Sources: Number of steam engines from Nuvolari et al. (2011); population levels from Wrigley (2007).

\subsection{The Dependent Variable: Human Capital}

Turning to our outcome variables, ${ }^{3}$ human capital is measured in three different ways: (i) in terms of primary schooling performances; (ii) as the share of skilled and unskilled workers; and (iii) as the density in the upper-tail of professional knowledge, that is, the share of highly skilled mechanical workers deemed important in previous work for the Industrial Revolution. These three different sets of human capital variables are derived from three main sources: the Church of England's baptismal registers of 1813-1820 (Shaw-Taylor et al. 2006); an English education census conducted in 1850 (Education Census 1851); and a record of educational diversity in provincial England, 1830-1870 (Stephens 1987).

2.2.1. Primary Education. Our first set of variables captures human capital formation associated with formal schooling. For this, two datasets of schooling are used: the number of day- and private schools existing in 1801, and the share of the population enrolled in day schooling in 1818. Both datasets were built using statistics from

3. The descriptive statistics are found in Appendix A. 


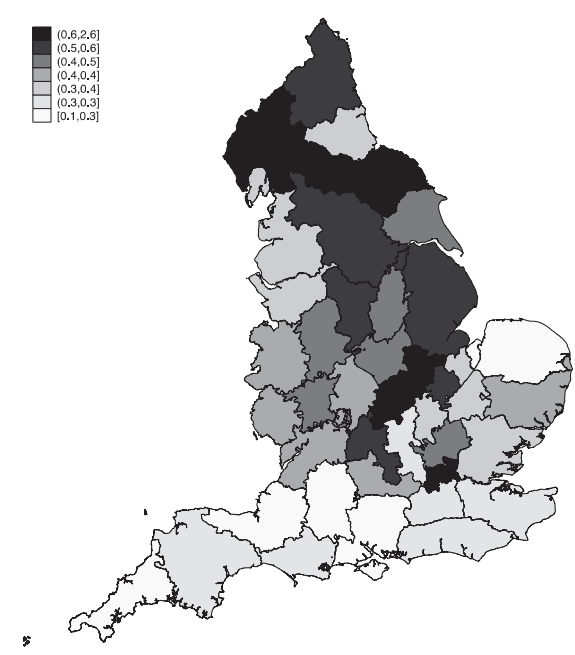

(a) Primary schools per 1,000 persons, 1801

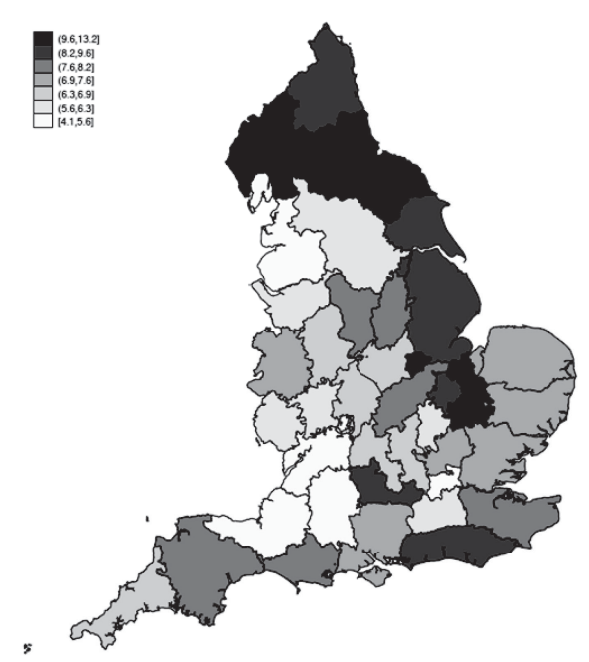

(b) Share of day-school pupils, 1818

FIGURE 3. Primary schools in 1801 and day-school pupils in 1818. The share of day-school pupils in Hampshire is the average of the neighbouring counties, that is, Dorset, Wiltshire, Berkshire, Surrey, and Sussex. Values for London are made equal to Middlesex. Sources: Schooling data from the Educational Census of 1851; Population levels from Wrigley (2007).

the Education Census (1851). Figure 3(a) shows the number of schools per 1,000 persons, and Figure 3(b) shows the number of day-school pupils per 1,000 persons. The correlation between the availability of primary schools per person and the share of pupils in the population is positive and highly significant. ${ }^{4}$ The number of primary schools per person varied greatly across the English counties. For example, Westmorland, the northern neighbour of the industrial county of Lancashire, had five times more schools per person and three times more pupils compared to Lancashire. Conversely, Westmorland had no steam engines at all compared to Lancashire's 265 engines.

Since school enrolment rates and the number of schools per person do not necessarily capture the school performances of the individuals involved, we also use the earliest available county-level male and female literacy rates. These literacy rates, reported in Stephens (1987), are based on signatures on marriage certificates in 1841. Because marriage usually took place between the ages of 25 and 35 in this period (Schofield 1985), those who signed their certificate are assumed to be born between 1806 and 1816. The male and female literacy rates by county are shown in Figure 4. This figure also illustrates gender inequality in literacy, that is, the county-specific difference between the male and female literacy rates relative to the male literacy rate.

4. The correlation between the log of the number of primary schools in 1801 and the share of day-school pupils in 1818 is 0.59 . 


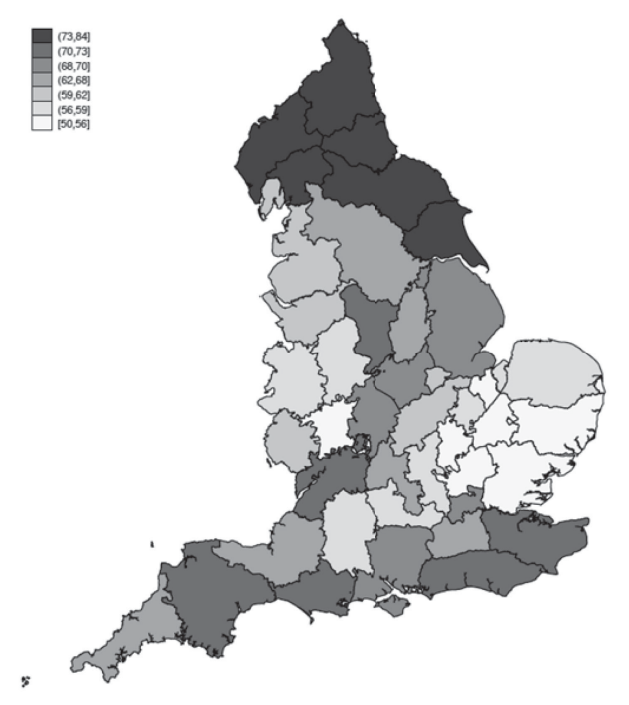

(a) Male literacy rates

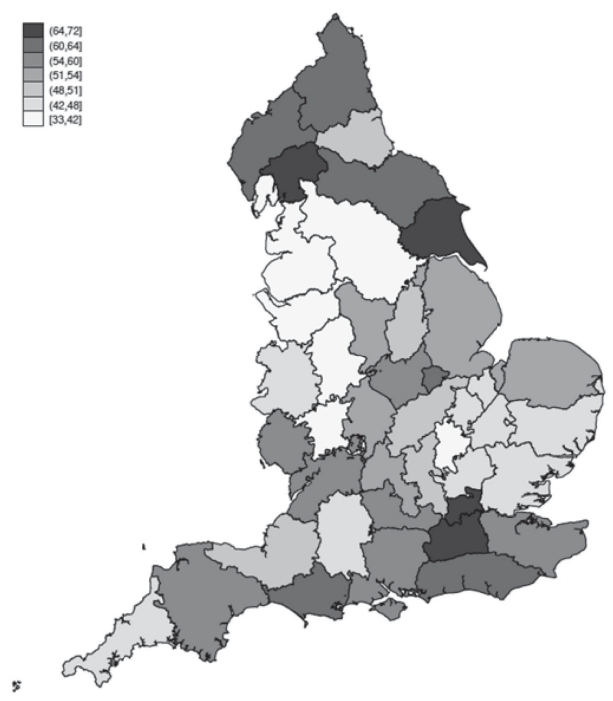

(b) Female literacy rates

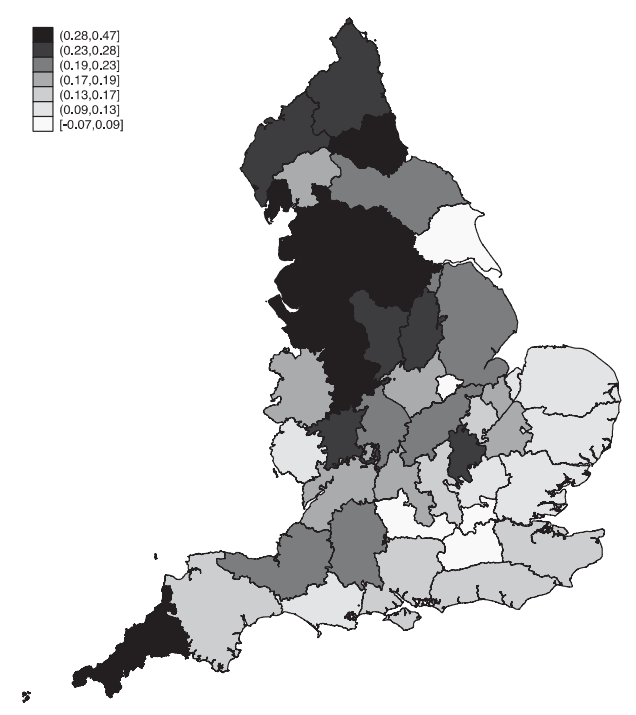

(c) Gender inequality in literacy

FIGURE 4. Literacy rates of individuals born c. 1806-1816. Values for London are made equal to Middlesex. Gender inequality is the male minus the female literacy rates over the male literacy rate. Source: Stephens (1987). 
Literacy in general was fairly common in Northern England, with three out of four men and two out of three women being able to sign their marriage contracts. Although literacy rates were comparatively lower in Southern England on average, the rates were still reasonably high: $60 \%-70 \%$ of all males and 50\%-60\% of all females had literacy skills. Still lower rates of literacy were found in Central England, especially the industrialised, western parts and particularly among women, with only one out of three females being able to read and write. The poor literacy attainment among women in England's industrial centre is mirrored by the high rates of inequality in literacy between men and women. Male literacy rates in the industrial counties of Lancashire and West Yorkshire were 20-30 percentage-points higher than those of females. In contrast, the counties surrounding London had less than 10 percentage-point gender differences and sometimes even higher literacy rates among women than men.

2.2.2. Working Skills from Occupations. Our second set of indicators of human capital formation concerns working skills derived from occupational titles. For this, we use a well-known and standardised historical classification system, the HISCLASS scheme. This system extracts information about the working skills required in order to perform the job described by an occupational title, as explained in Maas and van Leeuwen (2011). The HISCLASS scheme covers historical occupations from several European countries. We use HISCLASS's classification of British occupational titles.

The coding of occupational titles into HISCLASS's four skill-categories relies on a score given by labour historians on the basis of their assessment of the general educational attainment and specific vocational training needed for the job tasks. General educational attainment concerns three features regarding the intellectual competencies necessary to fulfil the tasks of the worker's job: (i) the worker's reasoning abilities; (ii) his or her ability to follow instructions; and (iii) his or her acquisition of the necessary language and mathematical skills needed to conduct the work. The worker's specific vocational training concerns the time-investment needed in three main areas: (a) the time required by the worker to learn the techniques necessary for carrying out the job; (b) the time needed to acquire the relevant information to conduct the work; and (c) the time needed to develop the competencies required for an average performance in a job-specific working situation. Based on these considerations, the HISCLASS scheme organises several thousand distinctly different historical occupational titles into four groups: highly skilled, medium-skilled, lower-skilled, and unskilled workers. ${ }^{5}$ For example, a "labourer" is classified as an unskilled worker in HISCLASS; a "weaver"

5. HISCLASS's coding of occupations by skill is time independent. Hence, if the task and thus dexterities required to perform a specific job changed during the period of consideration, then HISCLASS's skillcoding would fail to capture this, presenting a limitation of the scheme. However, if significant changes to a job description happened over time, it normally led to new or modified job titles. For example, spinning during the industrial revolution gradually evolved into numerous spinning categories, for example, cotton spinners, flax spinners, lace spinners, thread spinners, and mule spinners, all of which are skill-coded by HISCLASS. This means that, if new occupations emerged over time that required different skills compared to a previous and broader work category, then HISCLASS would pick this up. 
is lower-skilled; a "carpenter" is medium-skilled; and an "engineer" is highly skilled (see more examples in Online Appendix D.1).

The occupational titles used for the analysis have been collected from Anglican parish registers by the Cambridge Group for the History of Population and Social Structure and are described in Shaw-Taylor et al. (2006) and Kitson (2013). The system of baptismal registration, introduced by the English parliament in 1813, required the occupation of the father of the baptised child to be recorded by the Anglican Church. This enabled the Cambridge Group to build an early occupational census covering the whole of England in the period between 1813 and 1820 including 10,528 parishes. The data report the individual occupational titles of over 2.6 million adult males. Female occupations were hardly ever recorded by the church priests (except for the titles "pauper" and "widow"), explaining why women do not appear in the occupational dataset. Out of the 2.6 million male occupations recorded, we were able to classify some 1700 distinct titles into one of the four skill-categories described previously, covering $99 \%$ of the 2.6 million sampled adult males. ${ }^{6}$

Although the data represent the earliest reliable estimate for the occupational structure of the English male workforce at the time, the number of sampled males is not identical to an adult male headcount. First, since illegitimate children have no legal fathers named in the church books, no occupations have been provided for these cases. It is estimated that illegitimate children made up some $5 \%$ of all births in this period (Kitson 2013, p. 2). Second, some individuals may have been counted more than once over the seven-year period of observation, 1813-1820. Since more well-off fathers around this time tended to have slightly shorter spacing intervals between the births of their children (Cinnirella et al. 2017), and hence could potentially have fathered more children than their poorer counterparts during the seven-year data window, the dataset could mildly overestimate the number of skilled adults. However, unmarried men also do not appear in the data (Kitson 2013). Since celibacy rates were considerably higher among the rich than the poor (De La Croix et al. 2018), the dataset for that reason would underestimate the number of skilled adults, hence offsetting the previous effect.

Figure 5(a)-(d) shows the distribution of working skills, by county, for each of the four skill-categories. The overall patterns of the geographical distribution of working skills are rather clear. Unskilled work (panel a) was more prevalent in SouthEast England and was also concentrated to the north-west of London. For example, the agricultural county of Hertfordshire, situated north of London, had $60 \%$ of its workforce coded as unskilled. By contrast, the industrial county of Cheshire had half as many coded as unskilled, that is, around 30\%. Lower- and medium-skilled work displayed rather different geographical patterns to unskilled work. Lower-skilled work (panel b) was mostly concentrated in the west of England, particularly in the industrial centres and to the far north. The same is true of medium-skilled work (panel c), which is also found in the industrial counties, with a very high prevalence in Yorkshire

6. "Gentleman", "Esquire", "Pauper", "Widower", and "Slave" were excluded from the original data set. These titles, which make up some $1 \%$ of the sampled population, do not refer to an actual profession and hence cannot be coded using the HISCLASS scheme. 


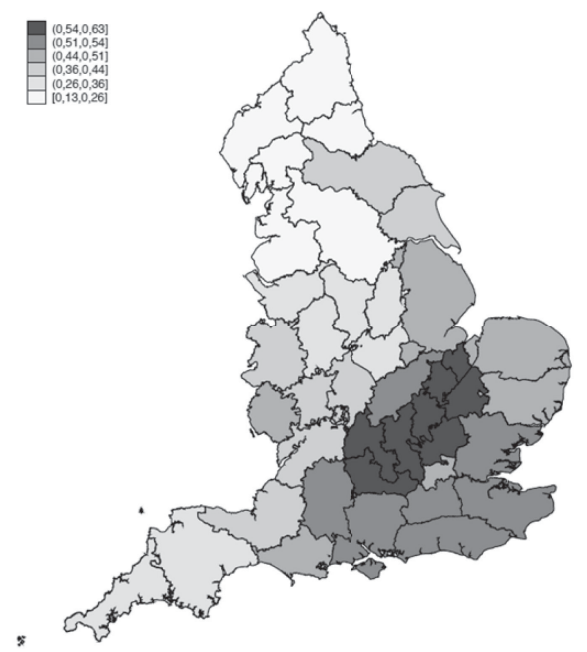

(a) Share of unskilled workers

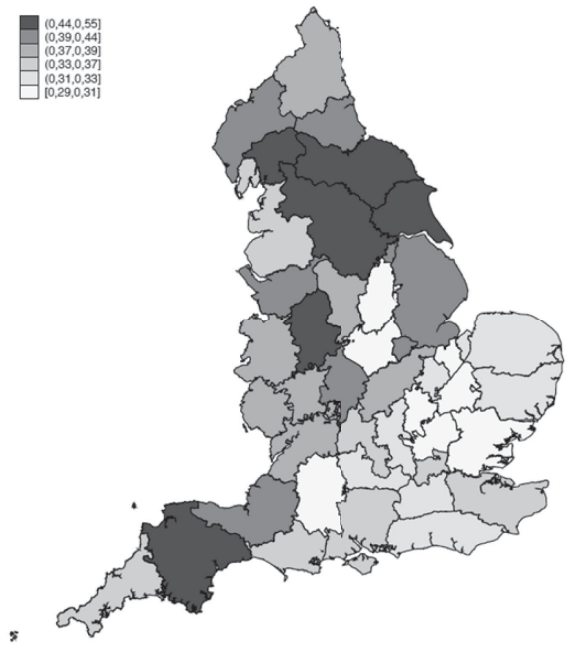

(c) Share of medium-skilled workers

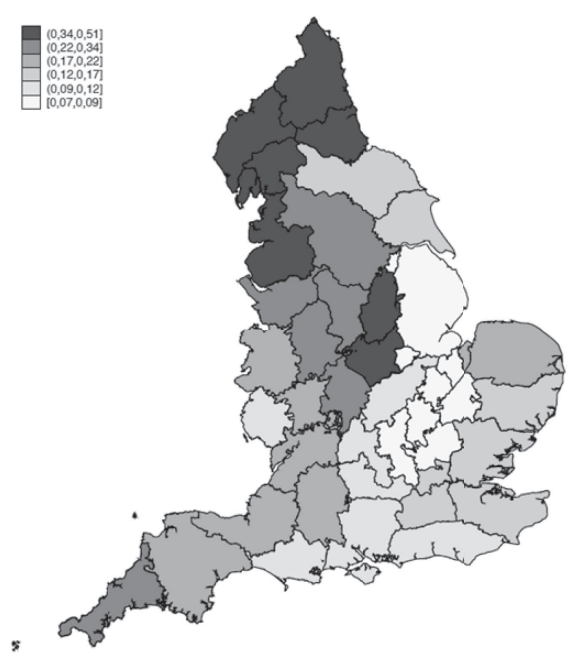

(b) Share of low-skilled workers

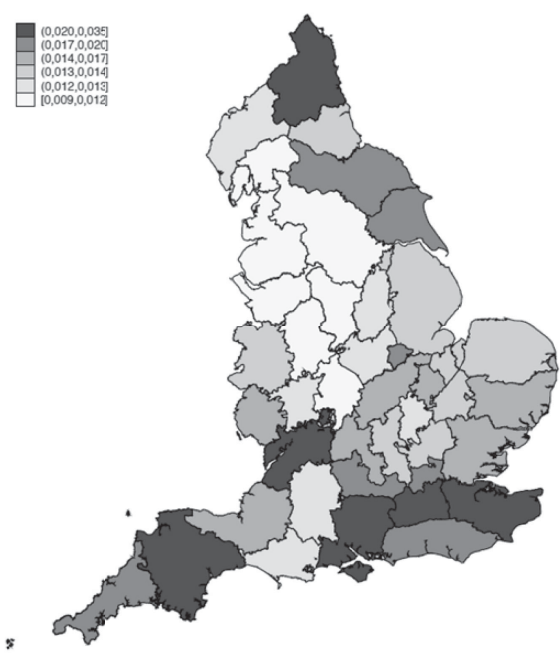

(d) Share of highly-skilled workers

FIGURE 5. Working skills from occupations, 1813-1820. Working skills are derived using the HISCLASS scheme (see text). Source: Shaw-Taylor et al. (2006).

West Riding. Unlike lower- and medium-skilled work, however, highly skilled work (panel d) was rather uncommon in England's industrial centre and was a phenomenon mostly found in Southern England, particularly in Devon and in the counties south of Middlesex and London, where many high-status land-owners lived.

Was working skills strongly correlated with primary education? The acquisition of schooling skills versus working skills are normally thought to have relied on very 
different factors. For example, Clark (2005) found that the attainment of literacy skills did not developed in tandem with the working-skill premium at the time. Table C.1 in the Online Appendix C reports the results of regressing the share of unskilled males on the share of literate males. The regression displays no statistically significant relationship between these two variables (columns (1) and (2)). Meanwhile, when occupational skills are broken down by category, there is a clear positive and statistically significant correlation between the share of literate men, on the one hand, and the shares of medium- and especially highly skilled men, on the other (columns (5)-(8)). These observations are consistent with earlier work by Nicholas and Nicholas (1992), demonstrating that medium- and highly skilled professions had much higher literacy rates than was the case among low- or unskilled professions, and by Mitch (1999) who reports a similar hierarchy of literacy by occupation. This suggests that technical change similarly influences working and schooling skills, albeit only to the degree that the two are correlated, which is not the case for lower- and unskilled workers.

2.2.3. The Upper Tail of Professional Knowledge. Three more indicators of human capital formation are introduced in order to try to examine the industry-specific training of workers. The first two measures concern the share of highly skilled mechanical workmen. These measures are based on work by Mokyr and co-workers, who have emphasised the importance of "the density in the upper tail of professional knowledge" vis-à-vis the average level of human capital present in the workforce (Mokyr 2005; Mokyr and Voth 2009; Feldman and van der Beek 2016; Zeev et al. 2017). To follow Meisenzahl and Mokyr (2012), it was not the average level of human capital that was important in the process of industrialisation, but rather the upper tail of the human capital distribution that mattered. In other words, technological change and the adoption of machinery improved the demand for high-quality workmen, such as engineers, mechanics, wrights, instrument makers, chemists, and so on. These highly trained workers (referred to as "tweakers" by Meisenzahl and Mokyr) were essential for the implementation and usage of new technologies, thus helping to bring about the Industrial Revolution.

Feldman and van der Beek (2016) have proposed a specific set of mechanical professions that supposedly capture these highly skilled mechanical workers. They distinguish between "non-routine" and "routine" mechanical workers. Routine tasks can be accomplished by following explicit rules, whereas non-routine tasks require more complex problem-solving. Based on our data, we have computed the countylevel shares of the occupational titles mentioned in their article as "mechanical" and "non-routine" (see the full list in the Online Appendix D.2). These titles form the occupational group, which Meisenzahl and Mokyr (2012) refer to as the "tweakers", that is, the density in the upper tail of professional knowledge. Since technological change may also have affected the demand for "routine" workers, we have also computed the county-level shares of "mechanical" and "routine" workers (Online Appendix Table D.2). 
Figure 6(a) and (b) illustrates the shares, showing that highly skilled nonroutine mechanical workmen were typically (though not exclusively) concentrated in England's early industrial counties, including Lancashire, West Yorkshire, and Shropshire. Consistent with the theory of Mokyr and others, counties that were more agricultural, such as Kent, Surrey, and Sussex, had lower shares of those workmen. The shares of highly skilled routine mechanical workmen are generally higher, but show a very similar geographical pattern as their non-routine counterparts, with high concentrations in England's industrial centres.

Finally, in order to capture skill formation in the industrial sector only, we restrict the analysis to workers that according to the HISCO-HISCLASS system are classified as belonging to the secondary (i.e., industrial) sector. The shares of skilled industrial workers, by county, are illustrated in Figure 6(c). Not surprisingly, these appear to concentrate in England's industrial centres.

\subsection{Confounding Variables}

Our regression analysis in what follows accounts for the confounding geographic and institutional characteristics of each county, as well as the county's pre-industrial developments. All of these characteristics may have contributed to industrialisation, as well as to the formation of human capital. In particular, pre-industrial developments, such as the early growth of cities and the prevalence of pre-industrial schools and apprenticeships, may have helped to foster both industrialisation and the later formation of human capital.

2.3.1. Geographical and Institutional Control Variables. Our first set of control variables capture the geographical characteristics of the English counties. Regional differences in geography linked to land quality and access to waterway transport may have affected the process of industrialisation by paying for the adoption of steam engines. Land quality may also have affected landownership and landowners' attitudes regarding educational institutions and hence the human capital formation of workers (Galor et al. 2009). Our analysis accounts for these matters by controlling for land quality, as calculated in Andersen et al. (2017) based on soil characteristics, as well as climatic characteristics, captured by average rainfall and temperatures, ${ }^{7}$ and the importance of waterways, measured as the total length of rivers to the total area of each county, also provided in Andersen et al. (2017). Figure 7(a) and (d) shows the county-level variation in rainfall, temperature, land quality, and waterways. Rainfall and waterways were common in the west of England; temperatures were high in the south; and land quality was high in the east of England. Our analysis also controls for the latitude of each county, measured in the location of the counties' administrative centres. A list of the administrative centres is found in Online Appendix E.

7. From http://www.metoffice.gov.uk/. 


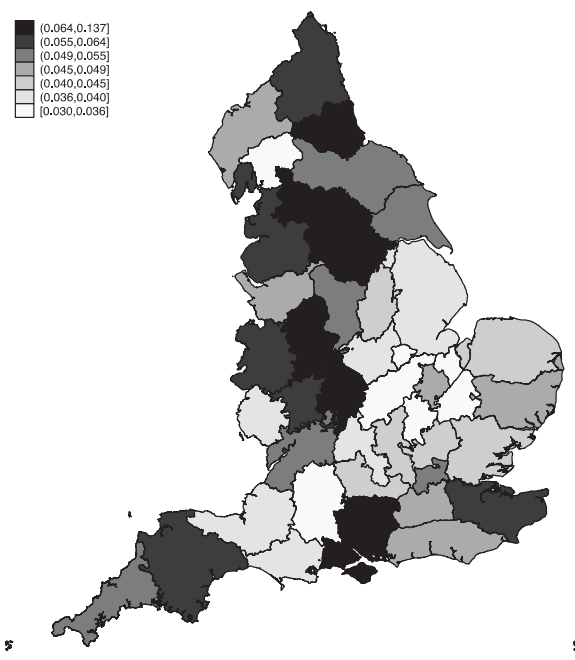

(a) Highly-skilled non-routine workers

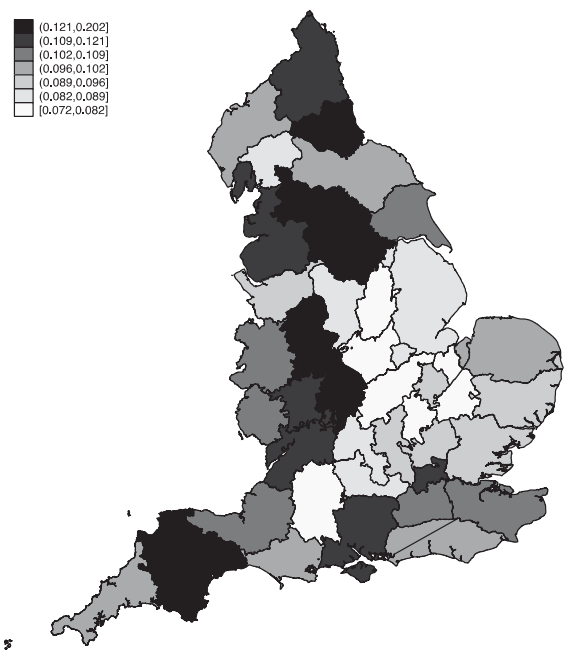

(b) Highly-skilled routine workers

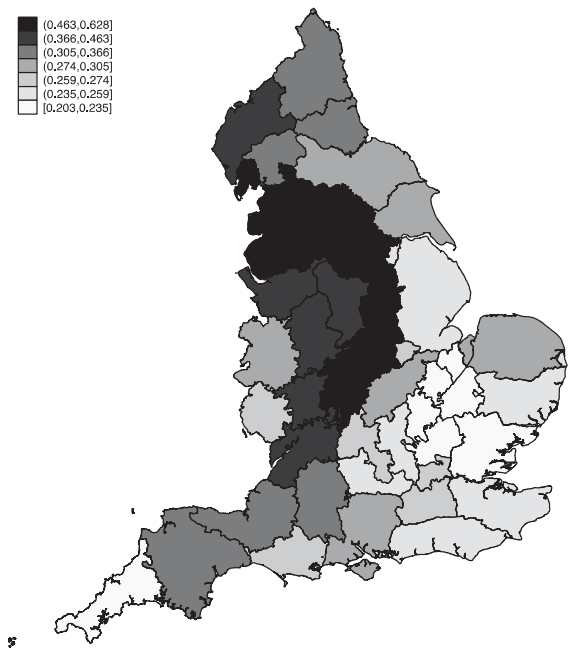

(c) Skilled workers employed in industry

FIGURE 6. Share of industry-specific occupational skills, 1813-1820. A full list of the highly skilled mechanical occupations can be found in Appendix D.2. Working skills in the secondary sector are derived using the HISCO/HISCLASS scheme (see text). Source: Shaw-Taylor et al. (2006). 


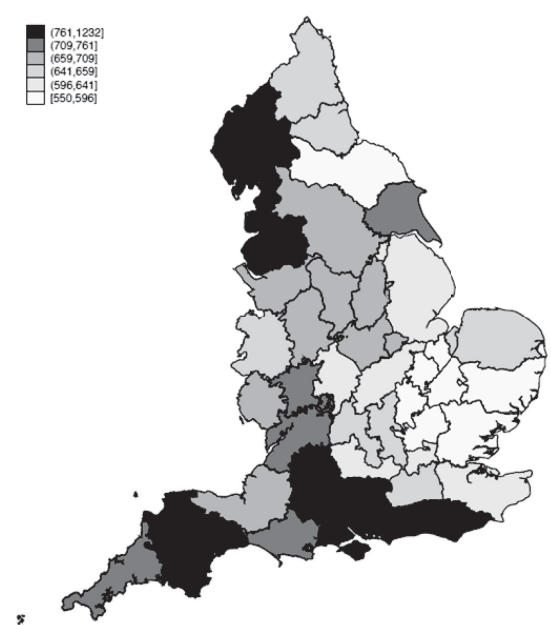

(a) Average annual rainfall (mm)

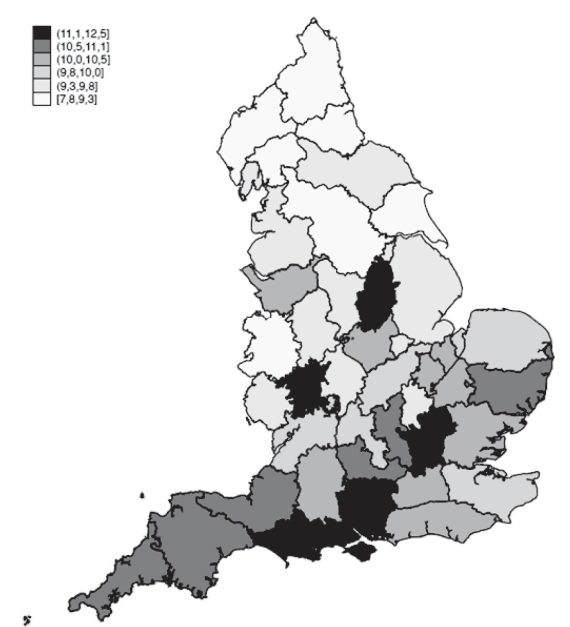

(b) Average temperature (Celsius)

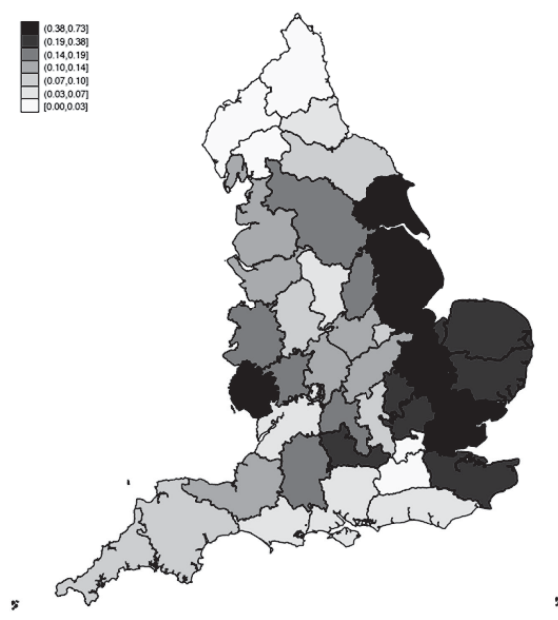

(c) Average land quality

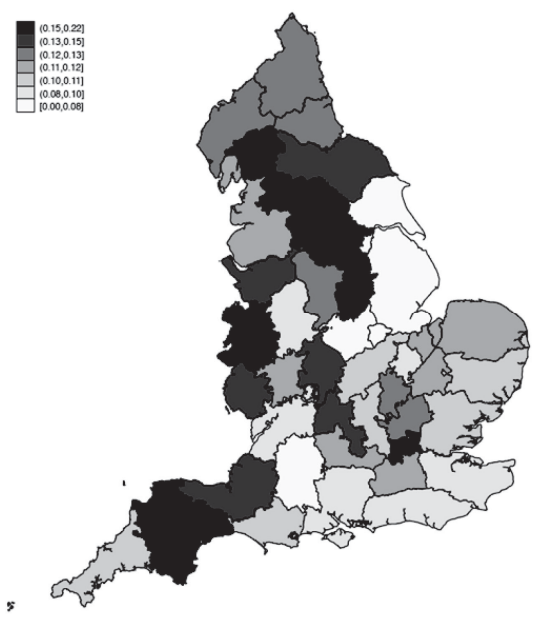

(d) Length of waterways to county size

FIGURE 7. Geographical control variables. Sources: Rainfall and temperature: http://www. metoffice.gov.uk/; Land quality and length of waterways: Andersen et al. (2017).

We also control for effects that might emerge as a result of the geographical location of a county vis-à-vis the possibilities for foreign influences. Trade or various forms of cultural impacts, stemming from contacts with non-nationals, may have stimulated the development of industry or the formation of human capital. Our analysis controls for this by using dummy variables accounting for counties that were bordering other 
countries (i.e., Wales or Scotland) or had access to the sea (maritime). Our study also controls for political institutions and their influences on industry and human capital formation. For example, the English Parliament, located in London, may have exercised a stronger influence on nearby counties than on countries situated further away. The analysis accounts for such effects using a dummy variable that equals one for the counties surrounding London (i.e., Berkshire, Buckinghamshire, Essex, Hertfordshire, Kent, London, Middlesex, and Surrey).

2.3.2. Pre-Industrial Control Variables. Finally, our study controls for the potential confounding effects stemming from regional variation in economic developments during the pre-industrial period. Counties that had many primary or secondary schools, were situated close to pre-industrial universities, or had many apprenticeships per person might have had higher levels of pre-industrial human capital than others. Similarly, counties that had higher population densities; faster population growth; or were more urbanised before the Industrial Revolution may have been more likely to industrialise or to successfully attract human capital.

We therefore control for these pre-industrial developments by accounting for the county-specific numbers of primary schools (Schools Inquiry Commission 1868a) and secondary schools (Schools Inquiry Commission 1868b) in 1700; for the distance to the nearest university in $1700 ;^{8}$ for the number of apprentices per 1,000 population c. 1711-1715 (Minns and Wallis 2013); for the population density in 1700 (Census of Great Britain 1841); for the population growth between 1600 and 1700 (Census of Great Britain 1841); and for the urbanisation ratio, which is defined as the population in cities with more than 5,000 inhabitants divided by the total population in 1700 (Bosker et al. 2013). County-level differences are reported in Figure 8(a)-(f).

\section{Empirical Analysis}

What was the effect of early industrialisation in England on human capital formation? To find out, we explore the empirical relationship between the county-level distribution of steam engines per person and the indicators of human capital described previously, while controlling for the confounding factors introduced in Section 2. Of course, an observed relationship between industrialisation and human capital formation is not necessarily causal. The process of industrialisation and that of human capital formation may have taken place independently, governed by common forces of economic development. In order to deal with this potential issue of endogeneity, we use exogenous variation in the distribution of carboniferous rock strata as an instrument for the number of steam engines per person installed by 1800. Coal is found in

8. Some of the sampled counties were near to the two English universities that existed at the time, that is, the universities of Cambridge and Oxford; others were closer to the two prevalent Scottish universities, that is, that of Glasgow and that of Edinburgh. Distance is the aerial distance (in $\mathrm{km}$ ) from the administrative centre of each county (see Online Appendix E) to the nearest university. 

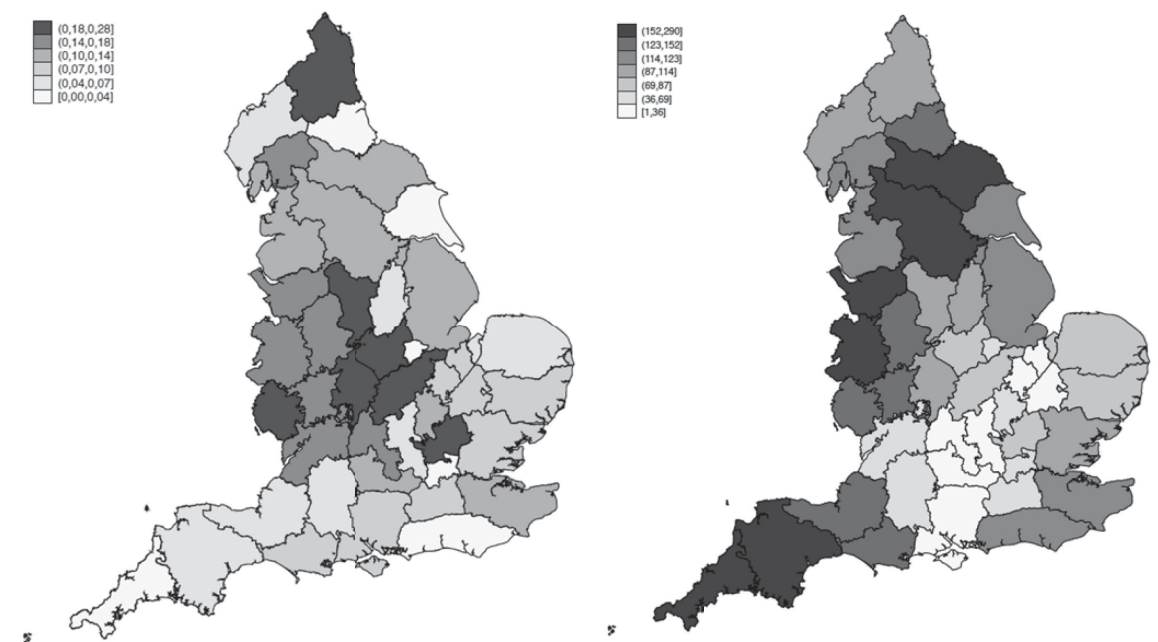

(a) Primary schools per 1,000 people, 1700

(b) Distance $(\mathrm{km})$ to the nearest university, 1700

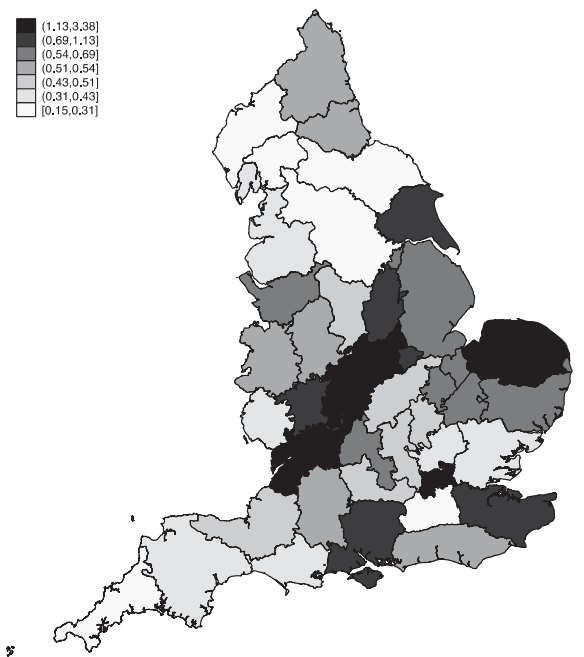

(c) Apprentices per 1,000 people, 1711-15

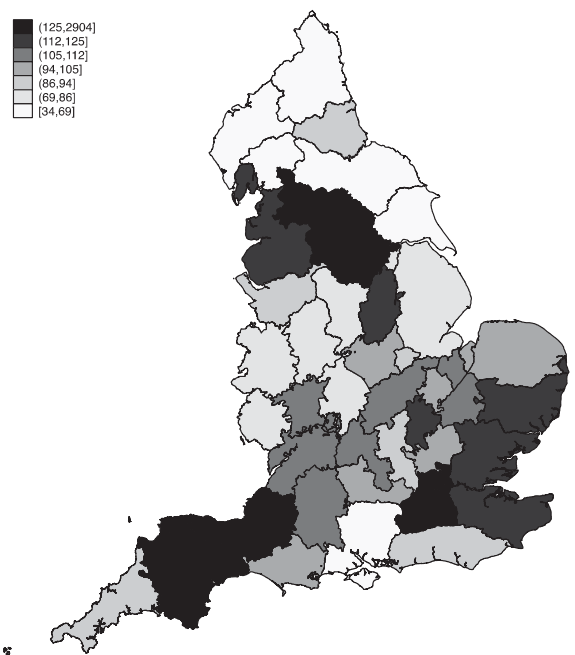

(d) People per square km, 1700

FIGURE 8. Pre-industrial developments, panels (a)-(f). The urbanisation ratio is the population in cities with more than 5,000 inhabitants divided by the total population. Population growth between 1600 and 1700 is relative to the population level in 1600 . The share of apprentices in Huntingdonshire is the average of the neighbouring counties, that is, Northamptonshire, Bedfordshire, and Cambridgeshire. The share of apprentices and the number of primary schools in London are made equal to Middlesex. Sources: Primary schools: Schools Inquiry Commission (1868a); Secondary schools: Schools Inquiry Commission (1868b); Urbanisation rates: Bosker et al. (2013); Population data are from the Census of Great Britain (1841), available at: http://www.visionofbritain.org.uk/census/GB1841ABS_1/6; Apprentices: Minns and Wallis (2013). 


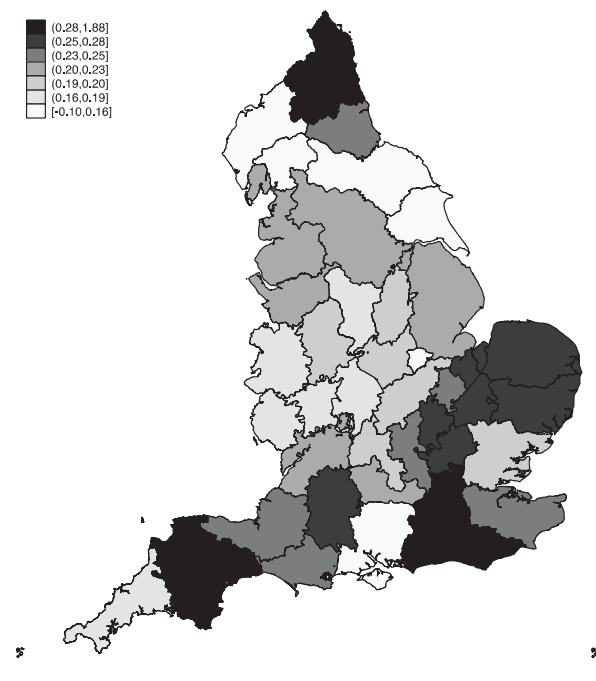

(e) Population growth rate, $1600-1700$

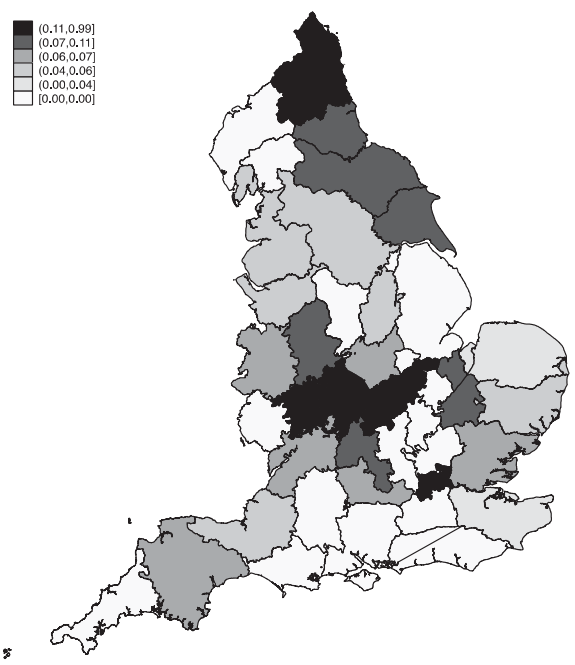

(f) Urbanisation ratio, 1700

FIGURE 8. Continued.

rock strata from the Carboniferous age, some 360-300 million years ago. Coalfields therefore habitually emerged near to these rock strata. Crafts and Mulatu (2006) have shown that coal abundance mattered for the location of steam-intensive industries, and Fernihough and O'Rourke (2014) that it linked to industry more generally. For example, Cullingford (1980) has pointed out that the county of Dorset, due to its absence of coal, was unable to compete with coal-rich counties, such as Lancashire, and so remained largely rural up until the present.

\subsection{Identification Strategy}

In what follows we will use the fact that the share of a county's carboniferous rock strata is highly correlated with the number of steam engines per person built and installed by 1800 , but that the county's concentration of carboniferous rock is independent of its indicators of pre-industrial development. Of course, carboniferous rock strata extend across several counties. This suggests there might be issues of spatial autocorrelation in the data. Moran's test for global spatial autocorrelation, reported in Table F.1 in the Online Appendix F, confirms that most of our dependent and independent variables are indeed highly spatially correlated. ${ }^{9}$ The diagnostic tests for spatial dependence in the econometric specifications (see Table F.2 in the Online Appendix F) show that the inclusion of our control variables in some cases remove the spatial correlation

9. Our estimates were carried out using the STATA commands for spatial regressions presented in Pisati (2001). The spatial matrix was constructed on the basis of the greatest Euclidian distance between two points in the data, with the global band set to 673,503 units. 


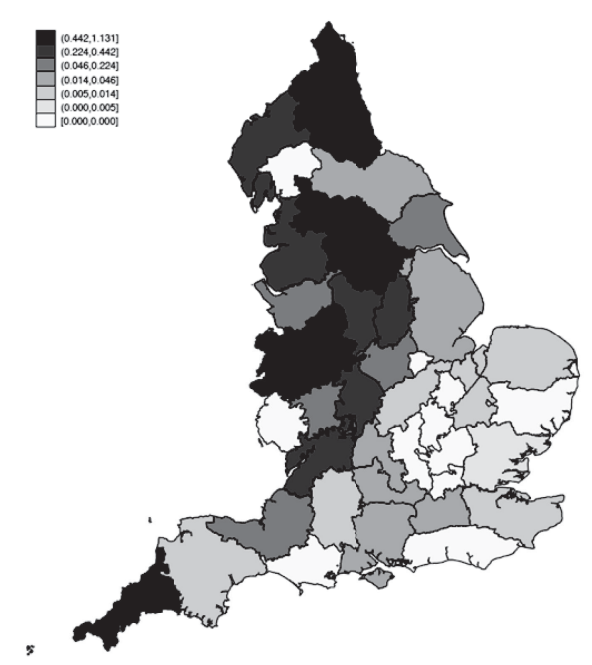

(a) Steam engines per 1,000 people in 1800

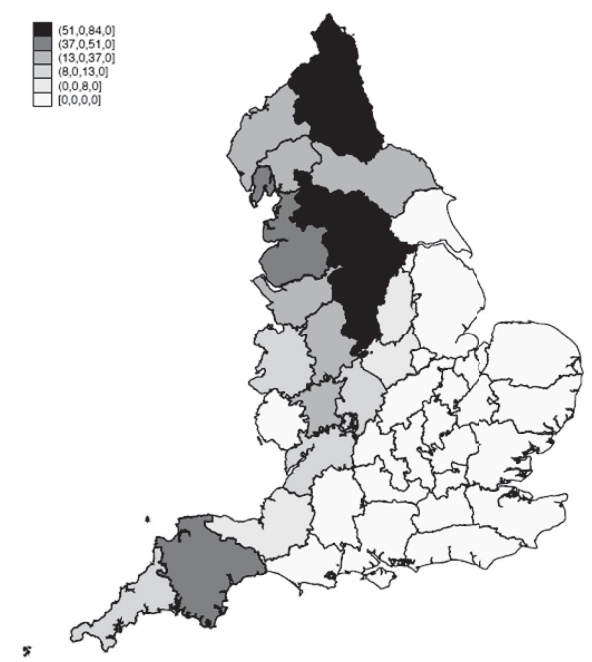

(b) Share of carboniferous rock strata

FIGURE 9. Steam engines per 1,000 people and carboniferous rock strata shares. Sources: Steam engines by county: Nuvolari et al. (2011); the share of rock strata by county were computed based on Asch (2005). [We are thankful to Alan Fernihough for preparing these data for us.] Population data: http://www.visionofbritain.org.uk/census/.

to the point where Moran's Index is no longer statistically significant. However, for completeness, and because the robust LM tests (also reported in Table F. 2 in the Online Appendix F) generally suggest that we should control for spatial autocorrelation in the error terms or for autoregressive processes in the outcome variable (or both), our regression tables systematically report the results of adjusting for spatial correlation.

Figure 9(a) illustrates the county-specific distribution of steam engines per 1,000 person and Figure 9(b) gives the share of each county's coverage of rock strata. The graphs suggest a high correlation between the two variables. Table 1 confirms a statistically significant relationship between them. Note that all reported coefficients are standardised. Column (1) reports a positive and strongly significant effect, with the share of carboniferous rock alone explaining $46 \%$ of the variation in the use of steam engines. The effect remains positive and strongly significant also after controlling for the confounding effects of geography (column (2)), institutions (column (3)) and pre-industrial developments as described previously (columns (4) and (7)). Moreover, columns (5), (6), (8), and (9) show that the effect is robust to controlling for spatial autocorrelation. $^{10}$

Consistent with the relationship reported in Figure 1, the three counties with the most steam engines, that is, Yorkshire West Riding, Lancashire and Northumberland,

10. Because some counties had zero engines (see Figure 1), the number of engines per person were log transformed using the formula: $\ln (x+1)$. 


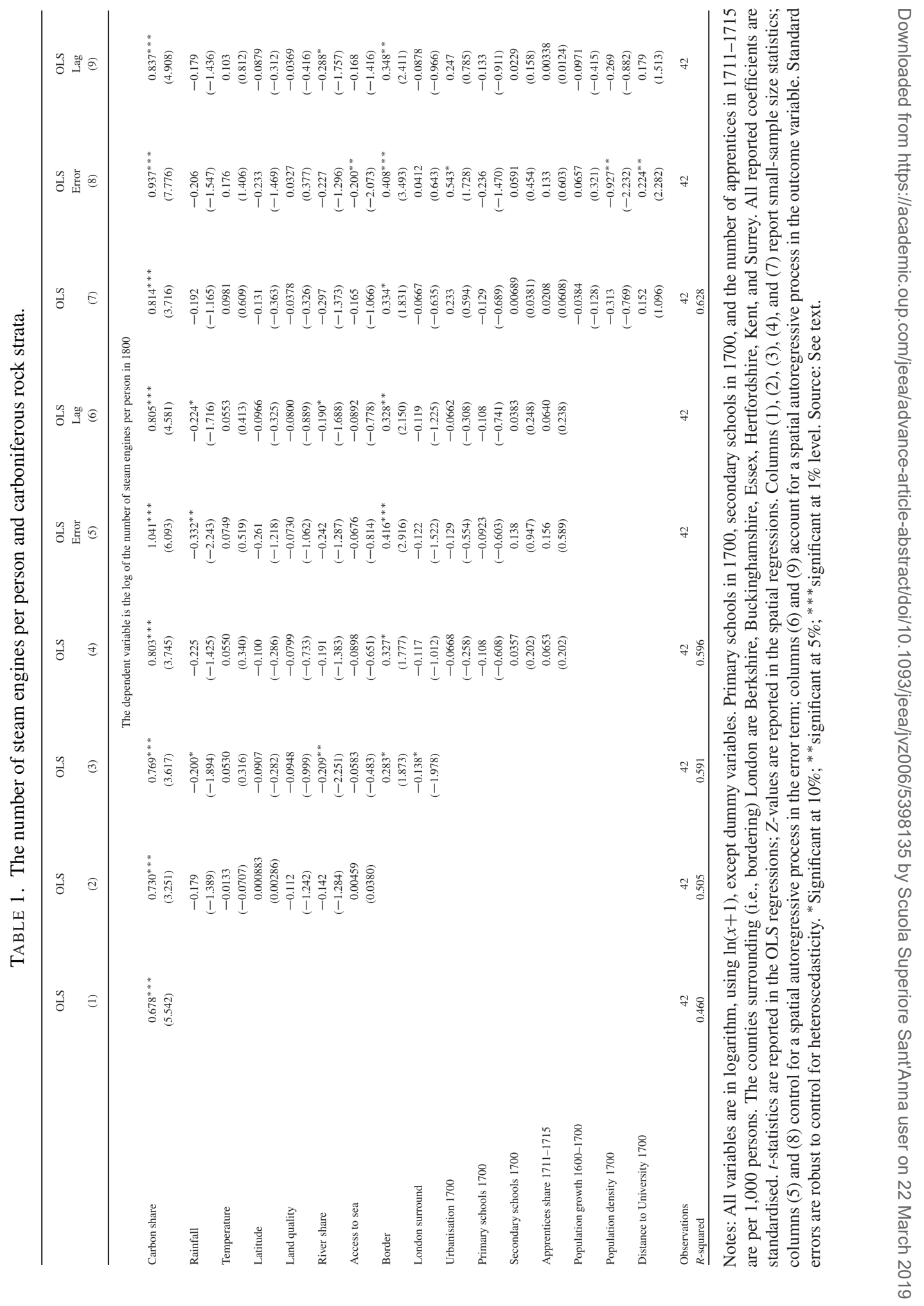


had some of the highest shares of carboniferous rock, ranging between $50 \%$ and $80 \%$ of the county's surface area. There were 15 counties that had more than 20 steam engines, and only one of these had no carboniferous rock. By contrast, 10 out of those 11 counties that had no steam engines also had no carboniferous rock at all.

The validity of using the distribution of carboniferous rock strata as an instrument for the distribution of steam engines per person is increased by the fact that carboniferous rock strata is not significantly correlated with our observed pre-industrial developments. Table 2(a) shows no statistically significant relationship between the share of carboniferous rock strata and our three proxies for pre-industrial population developments, including population growth between 1600 and 1700 (columns (1)(3)); population density in 1700 (columns (4)-(6)); and urbanisation in 1700 (columns (7)-(9)). Similarly, Table 2(b) shows no statistically significant association between the share of carboniferous rock strata and our four measures of pre-industrial human capital developments. These comprise the number of primary and secondary schools per 1,000 people in 1700 (columns (1)-(6)); the distance to the nearest university in 1700 (columns (7)-(9)); and the number of apprentices per 1,000 people in 1711-1715 (columns (10)-(12)). Tables 2(a) and (b) emphasise the importance of controlling for geography and institutions, which sometimes have statistically significant explanatory power with regards to pre-industrial developments.

\subsection{Empirical Method: Steam Engines and Human Capital}

Our 2SLS analysis is a cross-sectional estimate of the relationship between the number of steam engines per person in each county and our proxies for human capital. Specifically,

$$
H_{i t}=\alpha+\beta E_{i}+\boldsymbol{X}_{i}^{\prime} \quad \gamma+\varepsilon_{i t},
$$

where $H_{i t}$ is the level of human capital of county $i$ in year $t ; E_{i}$ is the $\log$ of the number of steam engines per person of county $i$ in 1800; $\boldsymbol{X}_{i}^{\prime}$ is a vector of geographical, institutional and pre-industrial characteristics of county $i$; and $\varepsilon_{i t}$ is the error term of county $i$ in year $t$.

In the first stage, the log of the number of steam engines per person is instrumented by the share of the county's carboniferous area, that is,

$$
E_{i}=\oslash_{1} C S_{i}+\boldsymbol{X}_{i}^{\prime} \oslash_{2}+\mu_{i}
$$

where $C S_{i}$ is the share of the county $i$ 's area covered by carboniferous rock; $\boldsymbol{X}_{i}^{\prime}$ is the vector of control variables included in equation (1); and $\mu_{i}$ is the error term.

\subsection{Work-Related Human Capital Formation}

We now turn to the regression results. We begin by looking at the effect of steam technology on working skills. Table 3 shows a statistically strong relationship between technical change and workers' average skill-achievements. All our regression tables report small sample-size statistics, with the exception of the models that account for 


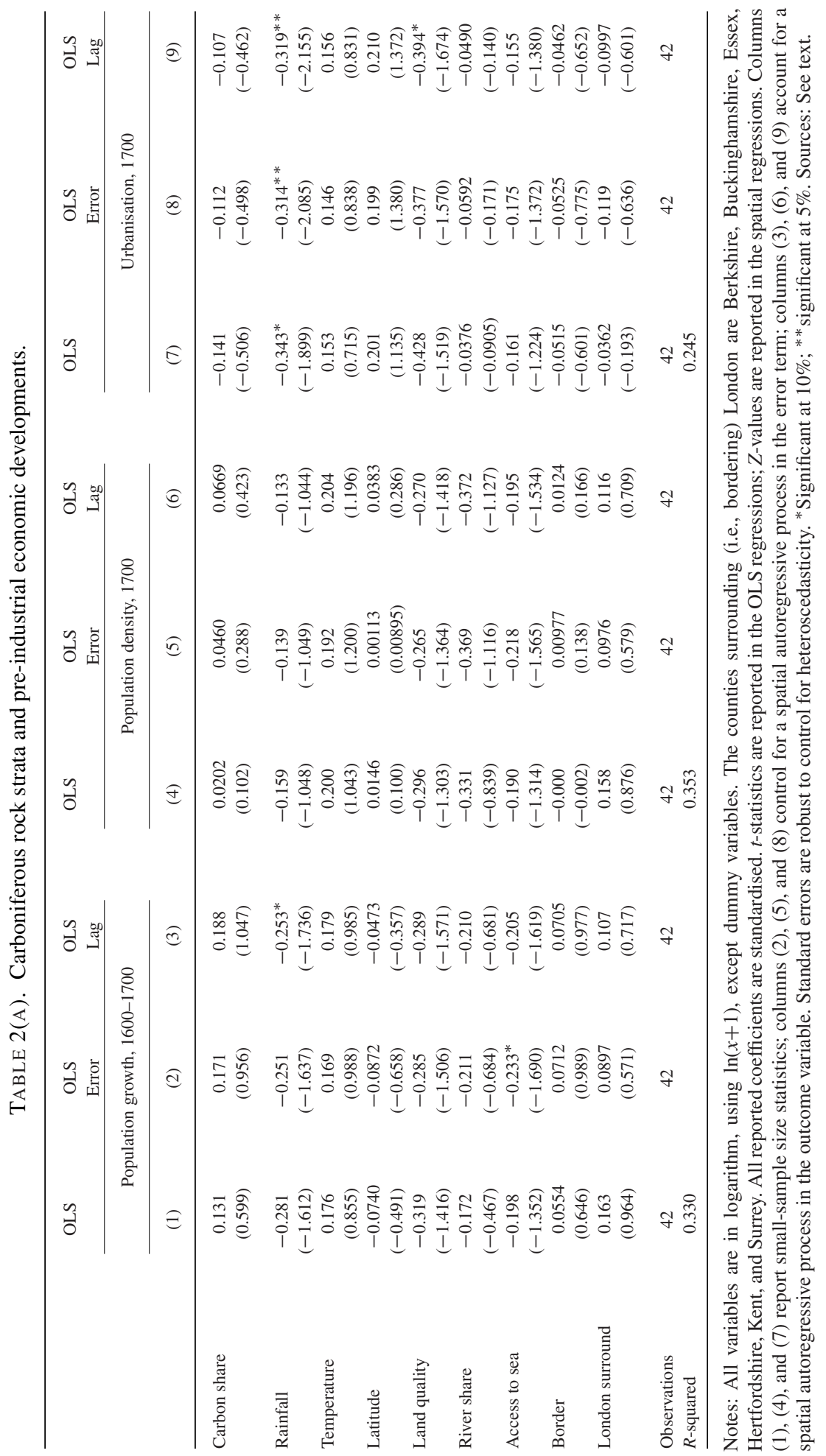




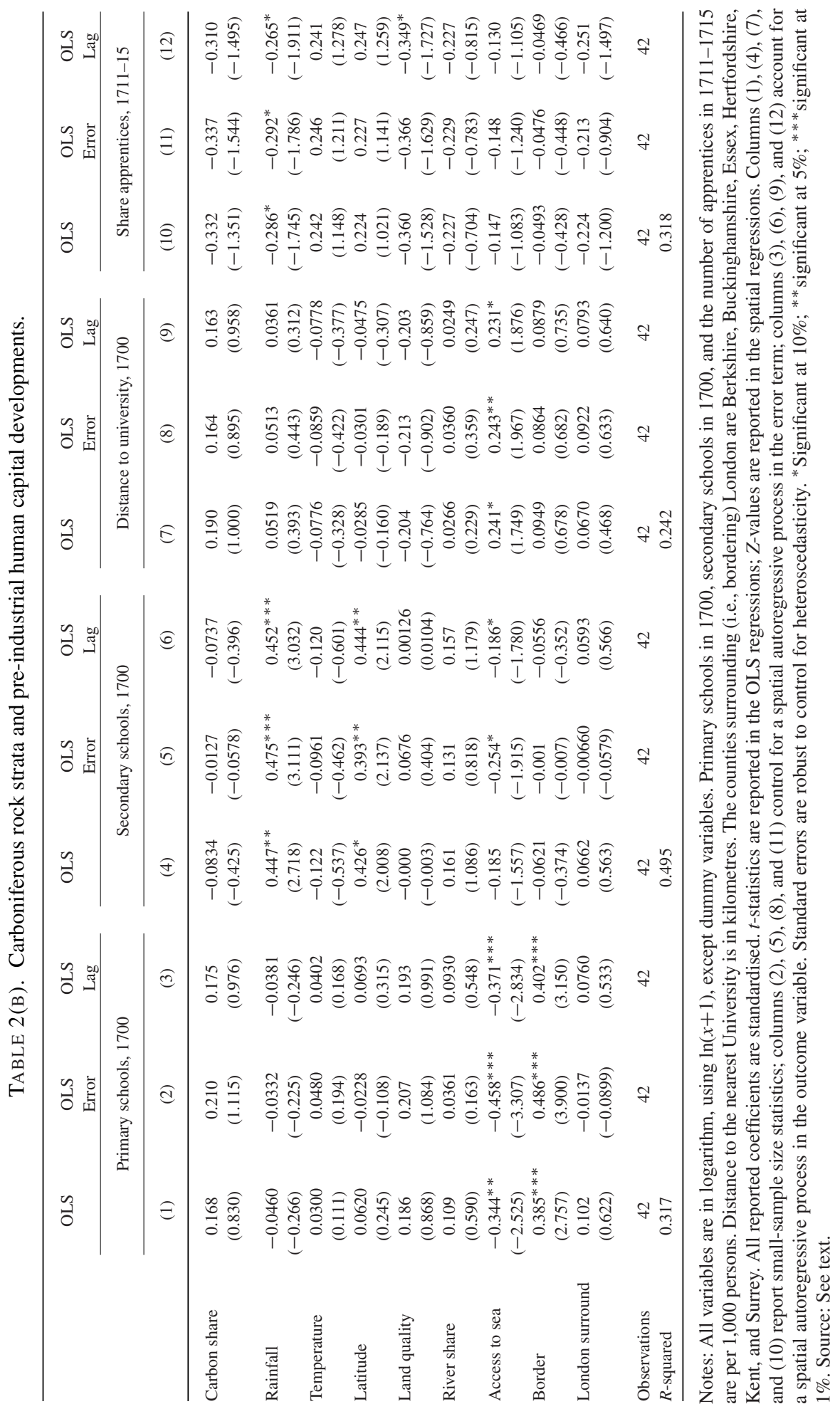




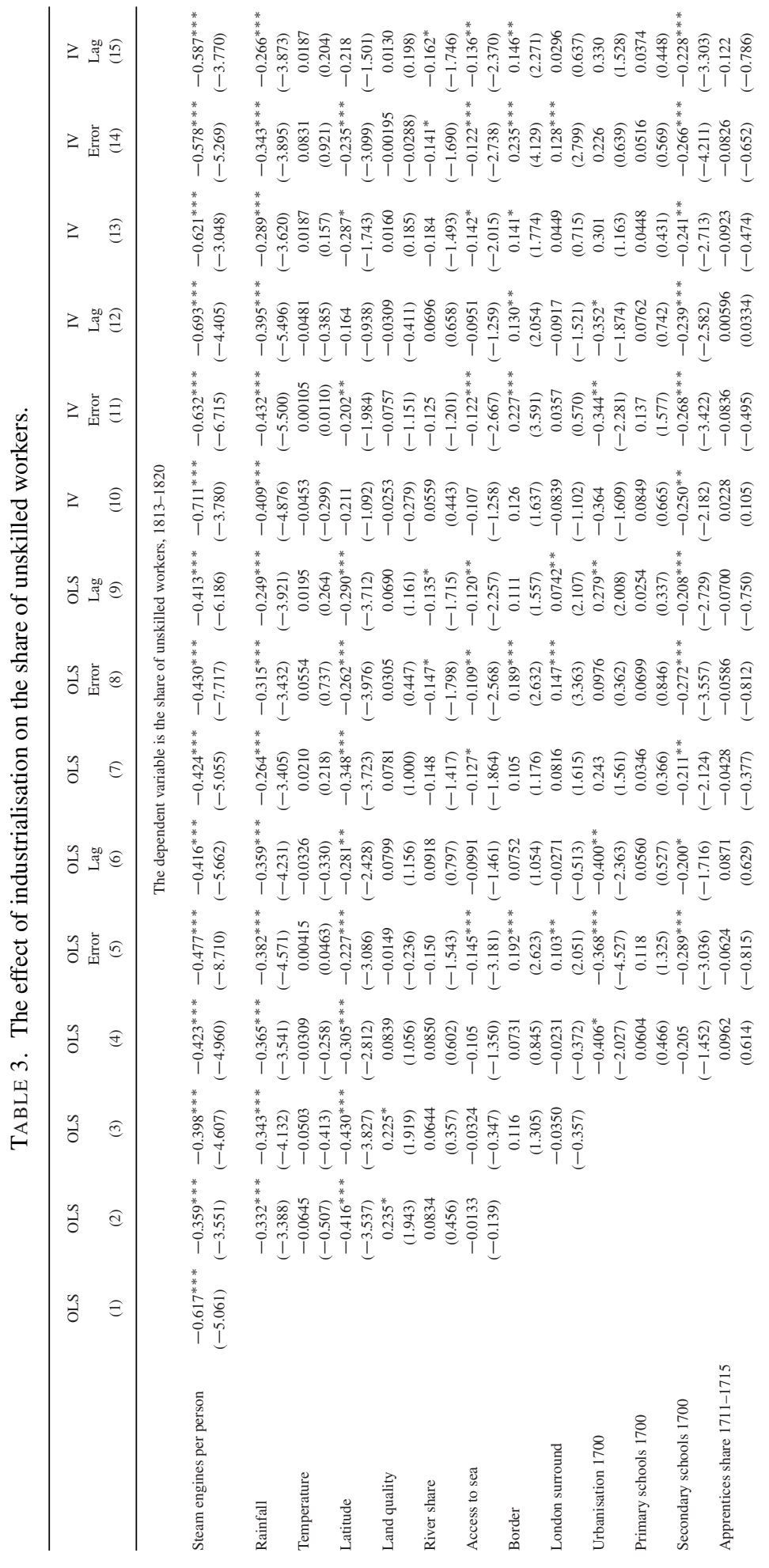




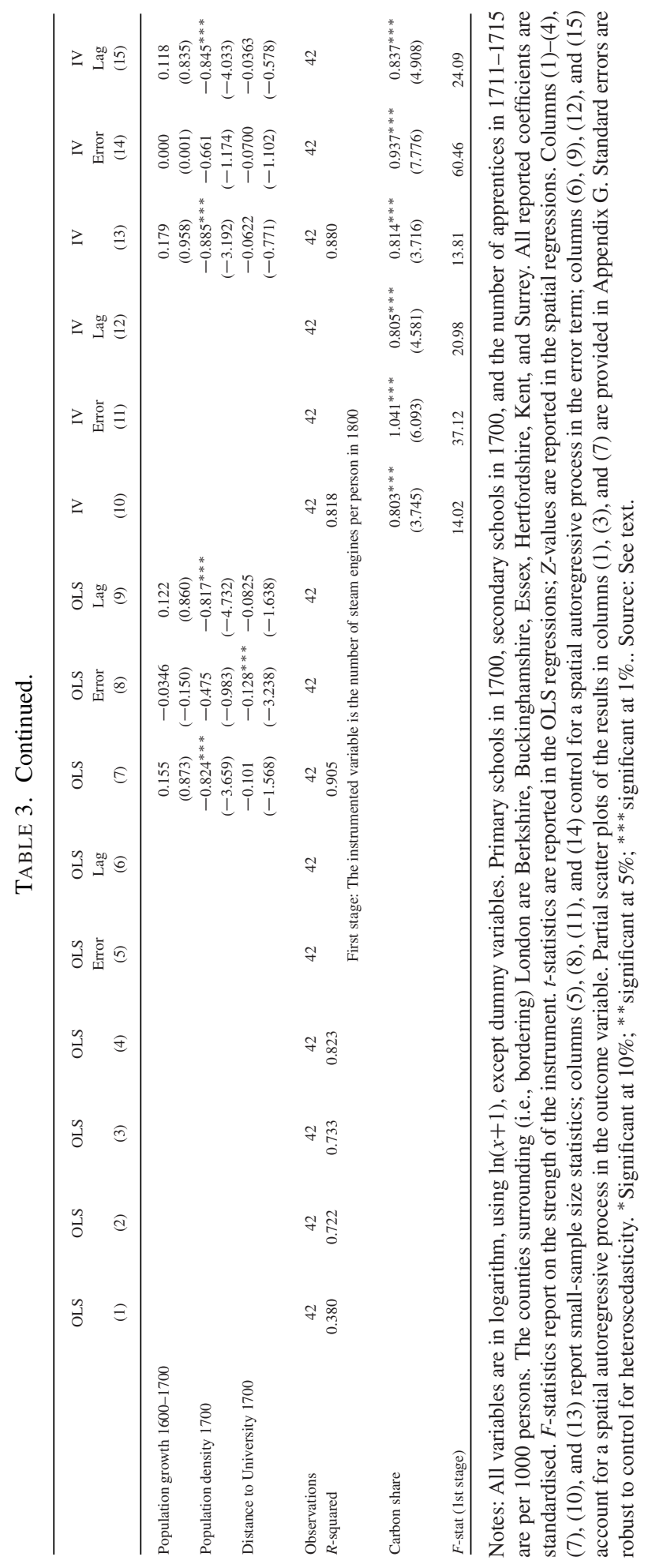




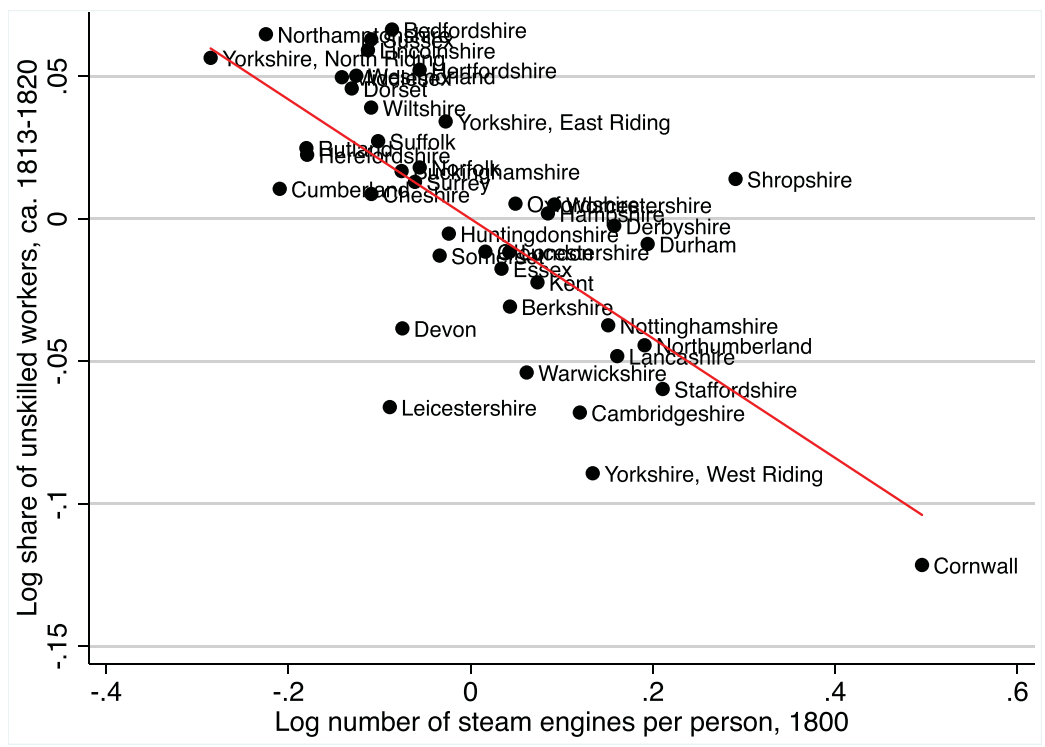

FIGURE 10. The shares of unskilled workers and the numbers of steam engines per person. This concerns the relationship between steam engines per person and the share of unskilled workers including all controls. See Figure G.1 in the Online Appendix G for the unconditional relationship. Source: See text.

spatial autocorrelation, which does not allow that option. Online Appendix G presents the partial-scatter plots for the main regression results, illustrating how the reported relationships change as we add controls. In order to check the robustness of the findings presented in what follows with regards to outliers, we perform a Jack-knife regression analysis in Section 4.6.

In the unconditional OLS analysis, reported in Table 3's column (1), steam engines per person and the share of unskilled workers were negatively statistically associated at the $1 \%$ level. The coefficient on steam engines per capita declines mildly as we control for geography (column (2)), institutions (column (3)), and pre-industrial developments (columns (4) and (7)), but it remains highly statistically significant throughout. The negative conditional relationship is illustrated in Figure 10. Columns (5) and (8) show that the results are robust to controlling for a spatial autoregressive process in the error terms, and columns (7) and (9) that they are robust to adjusting for a spatial correlation in the dependent variable.

Turning to the IV regressions, columns (10)-(15) show that the number of steam engines per person remains a highly statistically significant explanatory variable when we instrument the engines by the share of carboniferous rock strata. Columns (11) and (14) again account for the possibility of spatial autocorrelation in the error terms, and columns (12) and (15) for spatial correlation in the dependent variable. The absolute size of the coefficient on the (log of) steam engines per person is larger in the IV than the OLS regressions, which we suspect is due to measurement error. Still, the findings 
suggest a causal relationship, where a one standard-deviation increase in the log of steam engines per capita reduces the share of unskilled labourers by 0.58 standarddeviations (via the coefficient in column (14)). ${ }^{11}$ This implies that, if a county without steam had increased its number of engines per 1,000 persons to the level of Yorkshire West Riding, an important early industrial centre with 0.44 engines per 1,000 persons in 1800 , it would have led to a 13 percentage-points decrease in the share of unskilled workers (relative to a sample mean of $42 \%$ ). ${ }^{12}$ The size of the estimate implies that one more steam engine would have led to some 295 fewer unskilled workers, which makes good sense historically in terms of factory size. For example, steam-using factories in Manchester's cotton industry ranged from small establishments with 50-100 workers to large ones with more than 1,000 workers employed (Lloyd-Jones and Le Roux 1980). These numbers suggest that the formation of working skill could be directly related to the use of steam engines rather than a result of steam-engine externalities.

The coding of occupations into a total of four skill categories allows us to investigate the deeper relationship between intensity in the use of steam engines and working skills. In Tables 4-6, the skilled occupations are broken down into three outcome variables, that is, the shares of lower-, medium-, and highly skilled workers, respectively. Tables 4 and 5 show that more steam engines increased the share of lower- and medium-skilled workers, although for medium-skilled workers the coefficients are mainly economically and statistically significant in the IV analysis controlling for spatial autocorrelation. Table 6 shows that, although the coefficient for steam is mostly positive in IV analysis, the formation of highly skilled human capital is not statistically significantly influenced by the use of steam (at the $10 \%$ level). ${ }^{13}$ This conclusion may well be linked to the fact that many high-skilled professions, such as accountants, doctors, lawyers, and so on, were not directly connected to the use of steam engines in industry, but rather to tertiary-sector activities. ${ }^{14}$

Our findings thus indicate that early industrialisation was particularly conducive to the formation of low- and medium-level work-related human capital. For example, if a county increased its number of steam engines per 1,000 persons from zero to the level of Yorkshire West Riding, then this would have led to an 11 percentage-points increase in the share of low-skilled workers, and a 2.3 percentage-points increase in the share of medium-skilled workers (relative to sample means of $19 \%$ and $37 \%$, respectively). The higher concentrations of lower- and medium-skilled workers in steam-intensive areas, and the higher concentration of unskilled workers elsewhere, present a contrast the traditional workshop-to-factory narrative, whereby industrialisation allegedly caused

11. Throughout this section, we focus on the coefficients of the model reported in columns (14). This is the most fully specified model and the one most likely to give a lower bound of the magnitude of our observed effects.

12. Yorkshire West Riding represents the 85 th percentile.

13. Note that the four skill shares add up to one. This means that the effects of the (log of) steam engines per capita on the four skill categories add up to zero.

14. Highly skilled workers comprised less than $2 \%$ of the labour-force. 


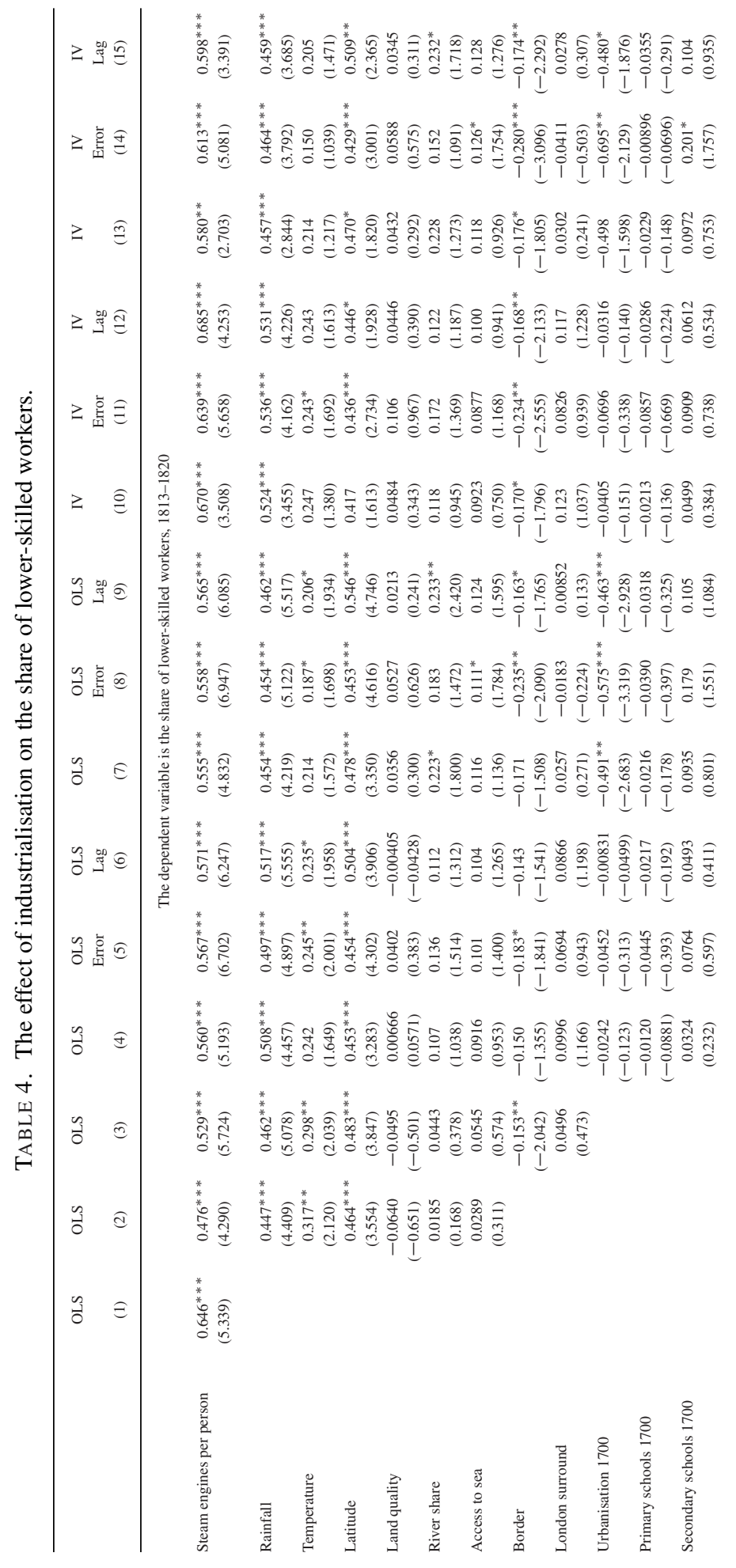




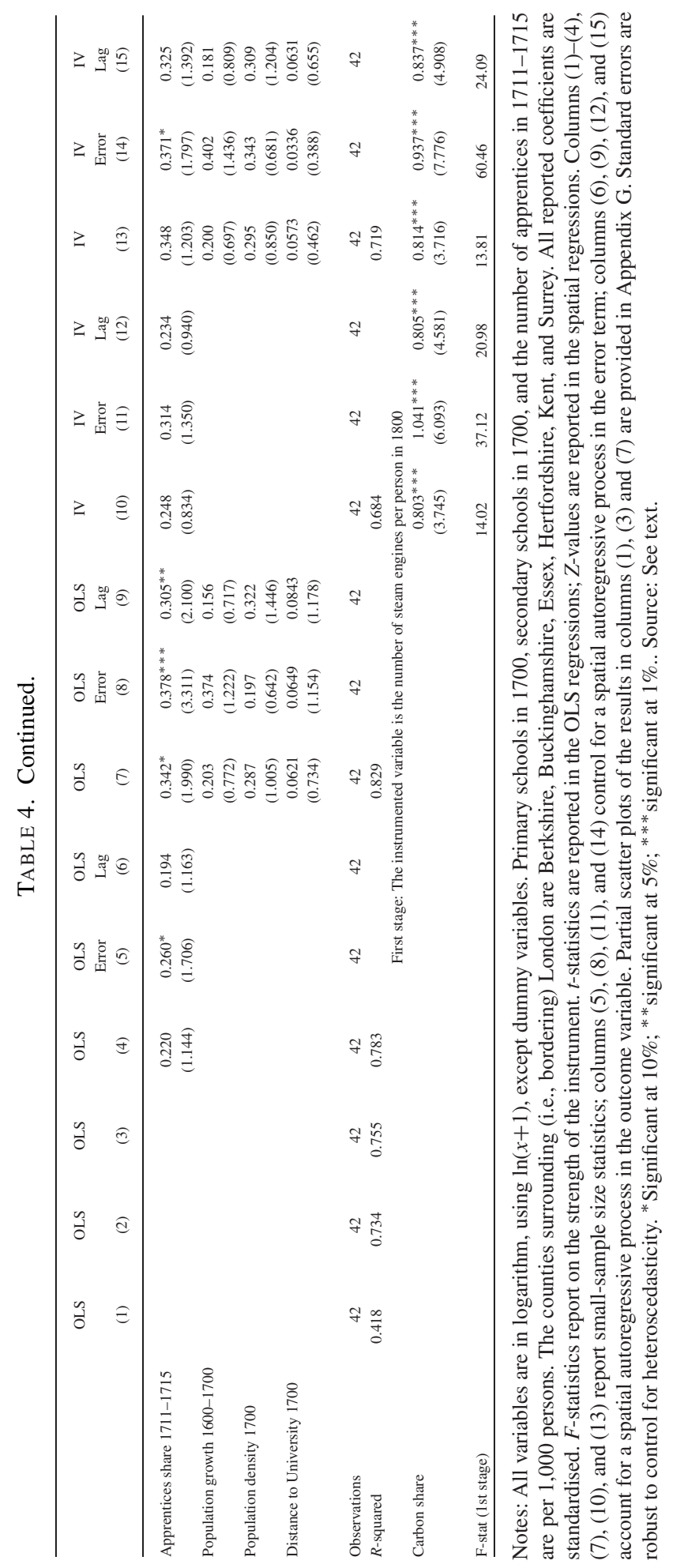




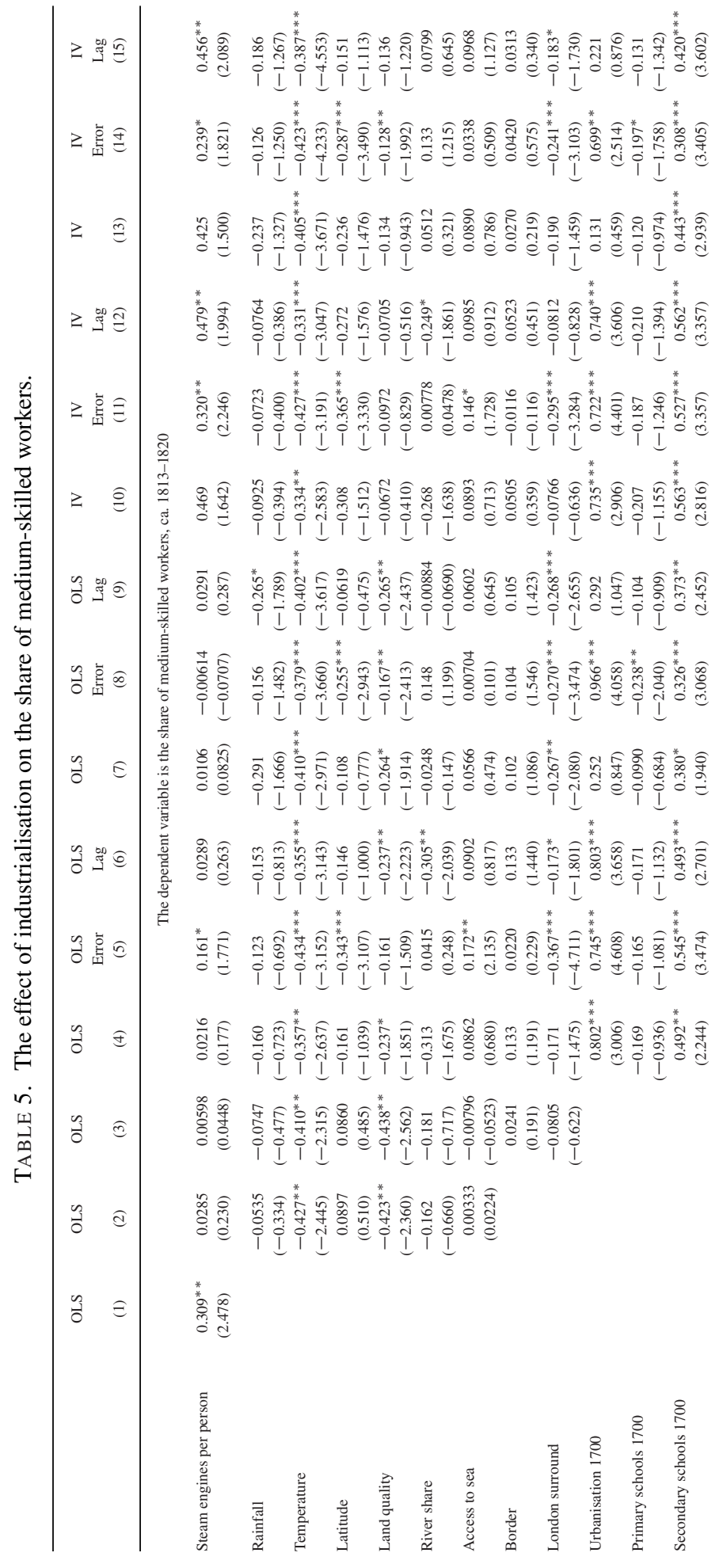




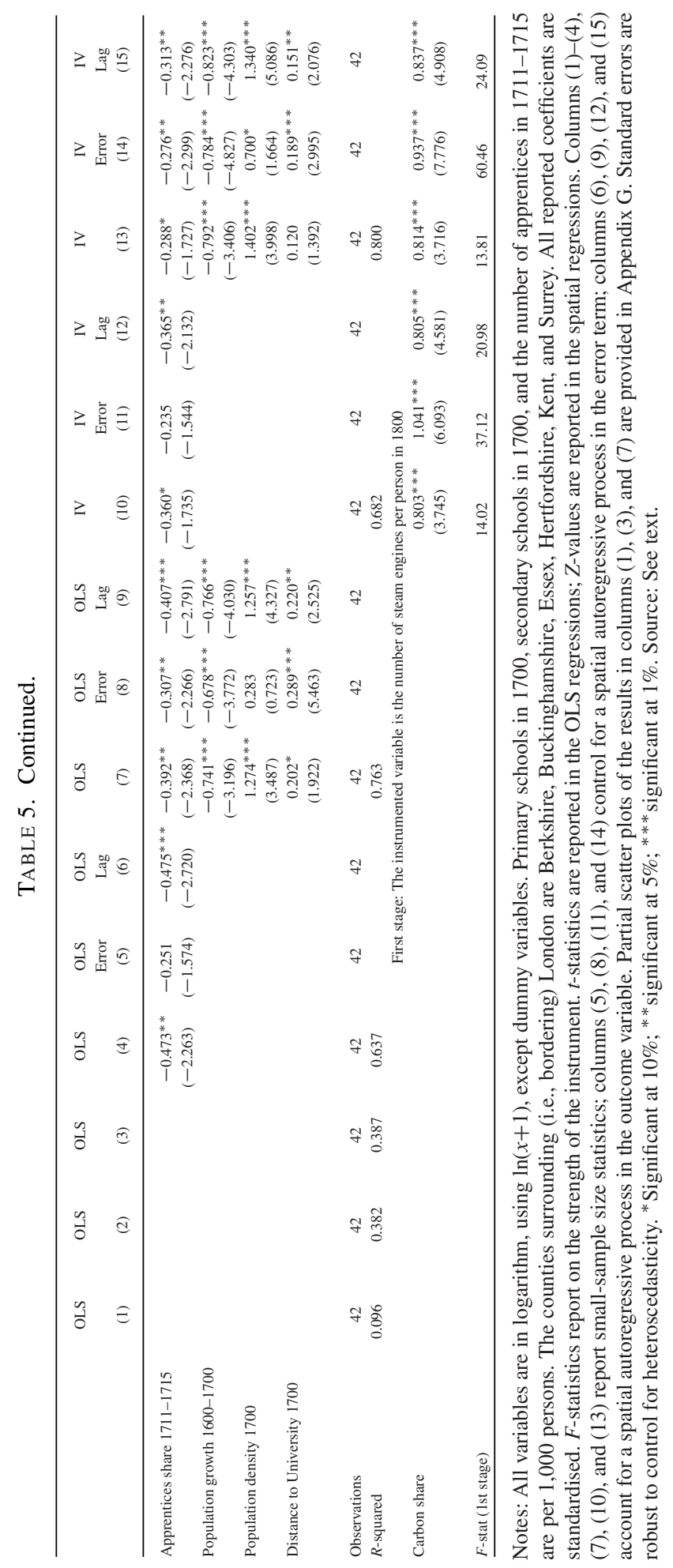




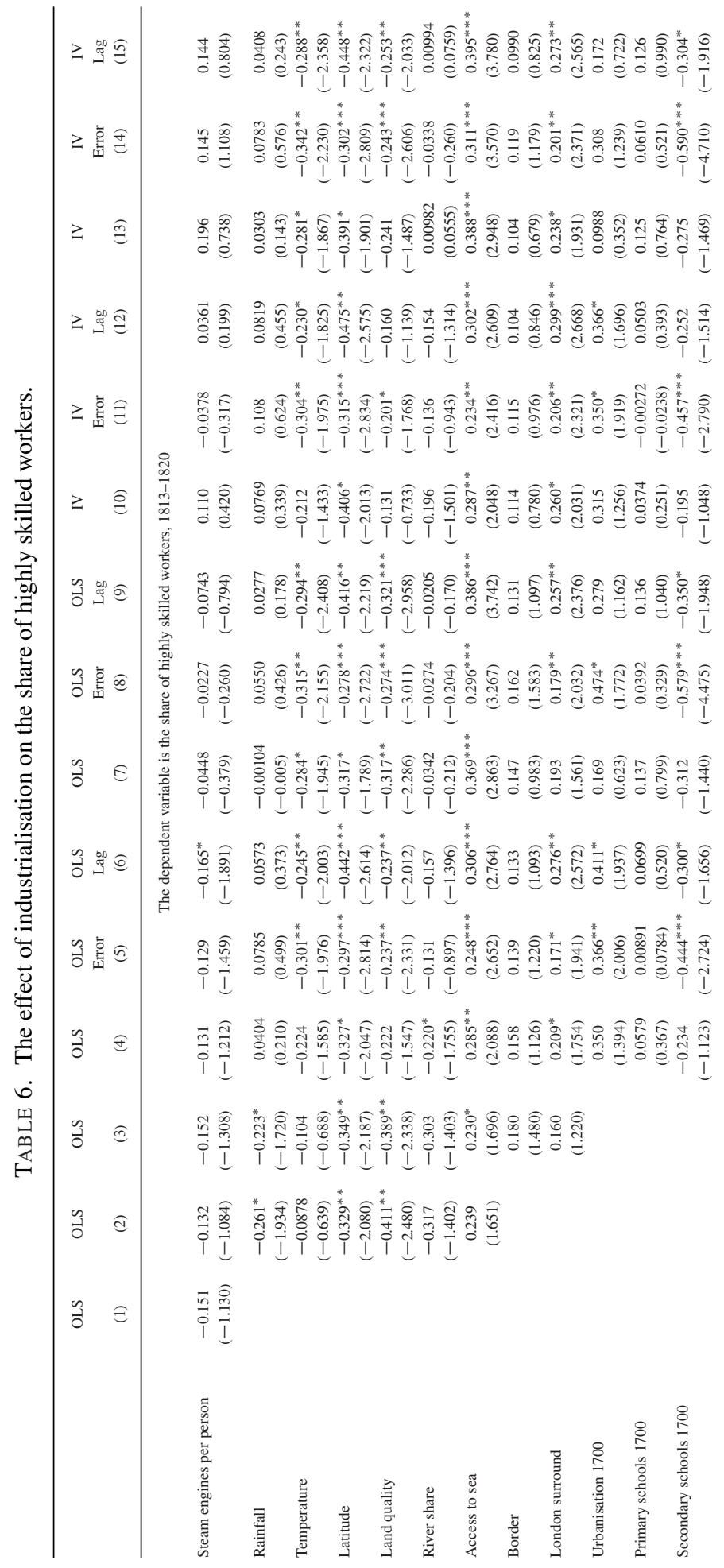




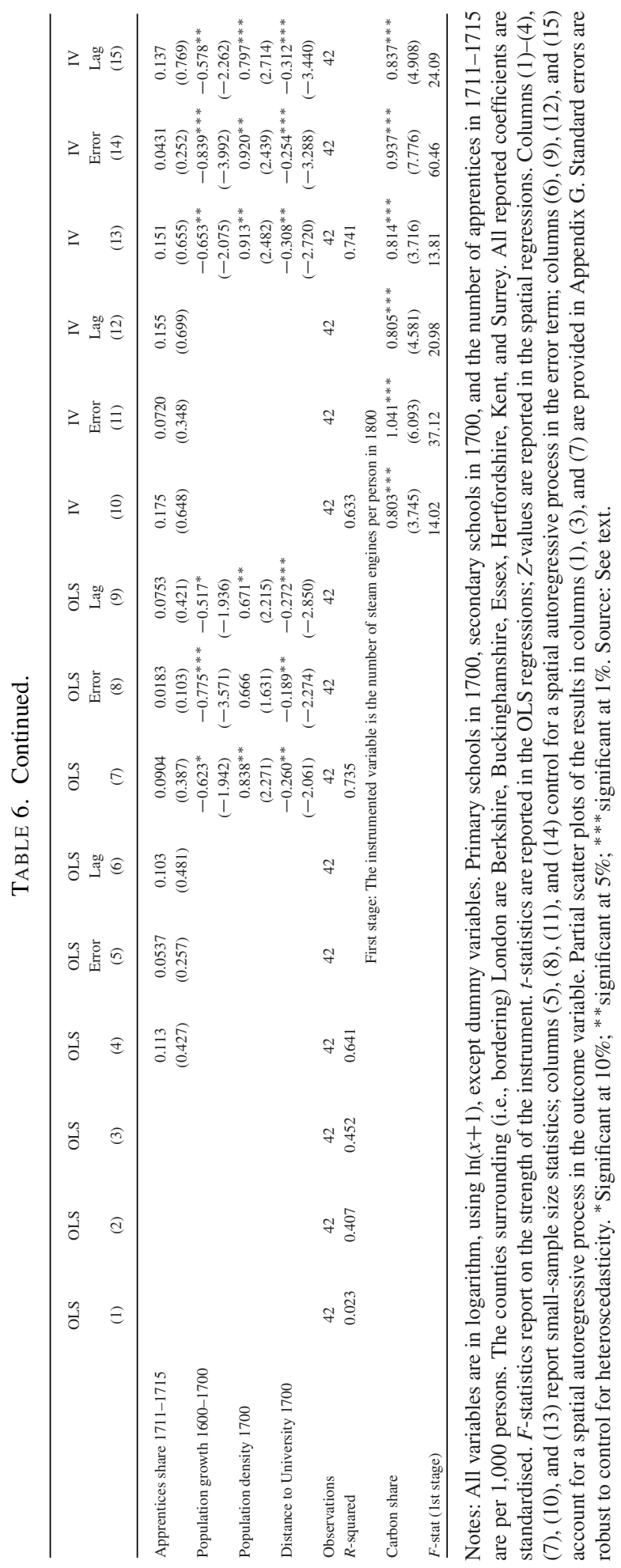


artisan, that is, medium-skilled workers, to drop down the skill ladder (e.g., Goldin and Katz 1998).

Of course, not all workers were involved in the steam-dependent sectors. In order to be certain that the skill formation we observe actually concerned occupations associated with the use of steam technology, we ran two additional analyses. The first analysis explains the shares of skilled workers that belonged to the secondary (i.e., industrial) sector, including occupational titles such as "cooper", "weaver", "spinner", "dyer", and so on. Consistent with our conclusions given previously, Table 7 shows that more steam engines per person caused higher shares of skilled, industrial-sector workers. More specifically, if a county with no steam engines had increased its number of steam engines per 1,000 persons to the level of Yorkshire West Riding, then this would have led to a 12 percentage-points increase in the share of skilled workers in industry (relative to a sample mean of $33 \%$ ).

The second analysis considers the argument presented in Mokyr (2005), Mokyr and Voth (2009), and Meisenzahl and Mokyr (2012) that the Industrial Revolution prompted the formation of highly skilled, mechanical workmen. Here, we used the two definitions proposed by Feldman and van der Beek (2016): one including mechanical non-routine workers and one including mechanical routine workers. Tables 8 and 9 confirm the Mokyr-Voth-Meisenzahl hypothesis in that more steam led to higher shares of highly skilled mechanical workmen, regardless of whether these workers were performing non-routine or routine tasks. These specifications generate highly statistically significant effects. In terms of magnitudes, if a county with no steam had increased its number of engines per 1,000 persons to the level of Yorkshire West Riding, then this would have increased the share of mechanical non-routine worker by 1.6 percentage-points, and the share of mechanical routine worker by 3.4 percentagepoints (relative to sample means of $5 \%$ and $10 \%$, respectively).

\subsection{Primary Education}

Having established a positive and significant effect of the number of steam engines per person on work-specific human capital formation, we now turn to their effect on primary schooling. Table 10 reports the result of regressing the number of primary schools per 1,000 inhabitants in 1801 on the number of steam engines per person installed by 1800. The coefficients are significant and negative in the OLS regressions (column (1)), also after controlling for geography (column (2)), institutions (column (3)), and pre-industrial developments (columns (4) and (7)). The IV estimates in columns (8)(15) show the effect is causal. Increasing the number of steam engines from zero to the number of engines per 1,000 persons in Yorkshire West Riding, the number of schools per 1,000 people would have decreased by $64 \%$ (relative to a sample mean of 0.47 schools per 1,000 people). Similarly, Table 11 reports the results of regressing the rates of day-school enrolment in 1818 on the steam engines per 1,000 persons in 1800. Here, the coefficients of steam engines are negative throughout, although rarely statistically significant at the $10 \%$ level. 


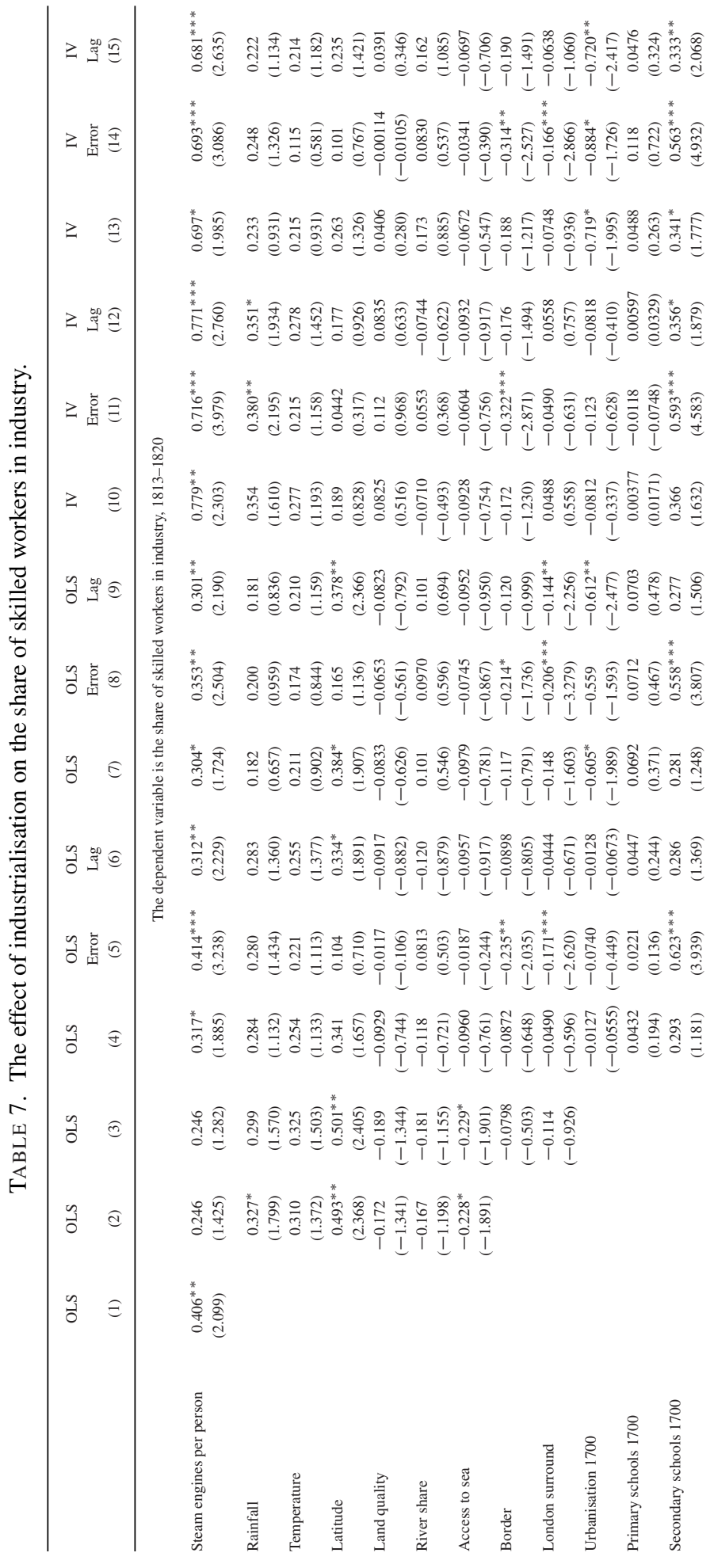




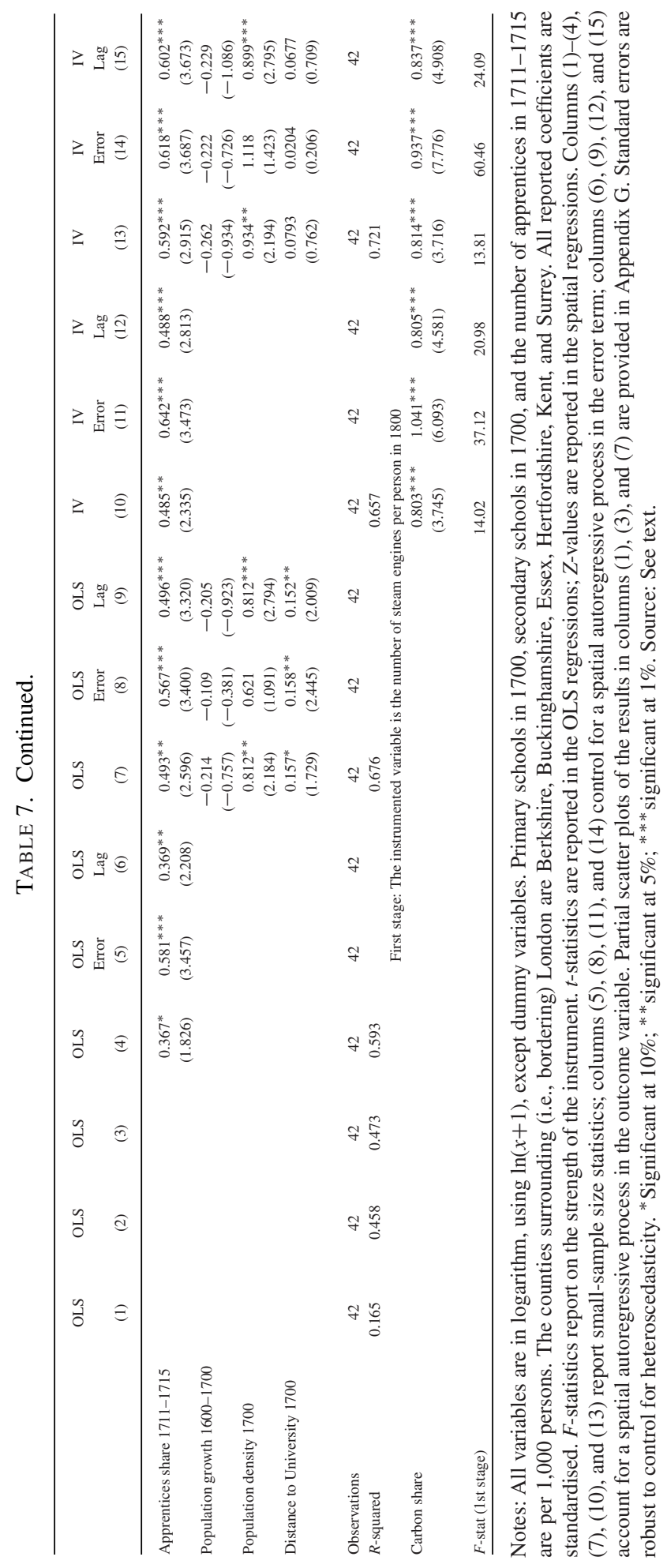




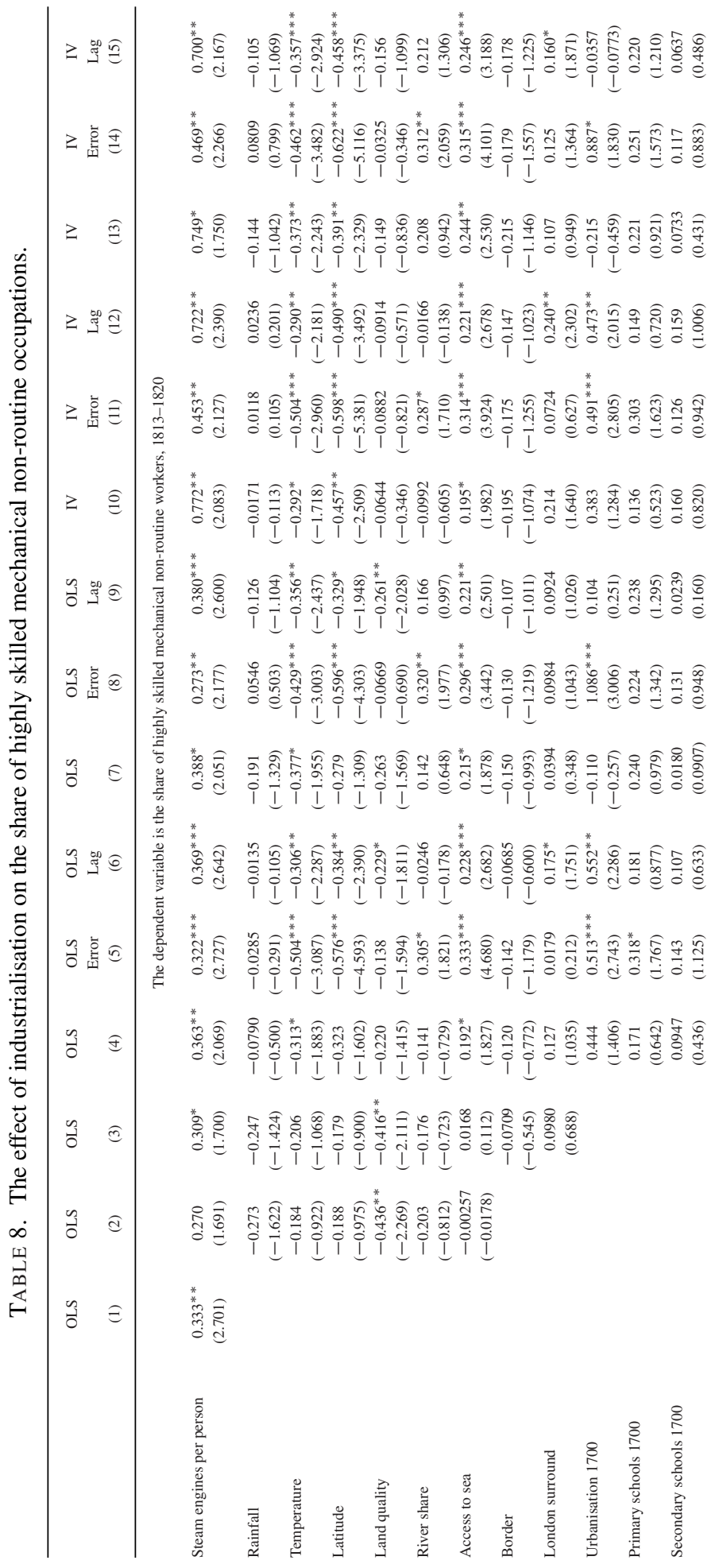




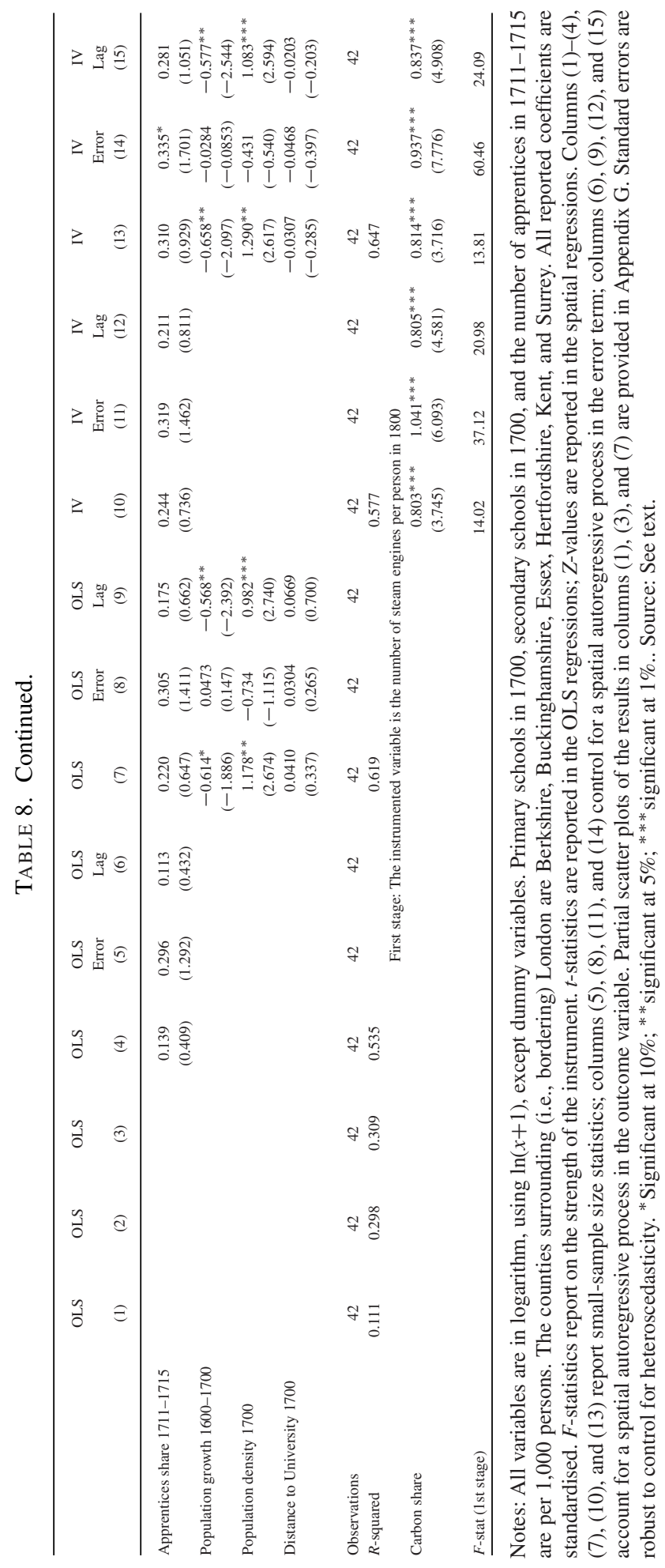




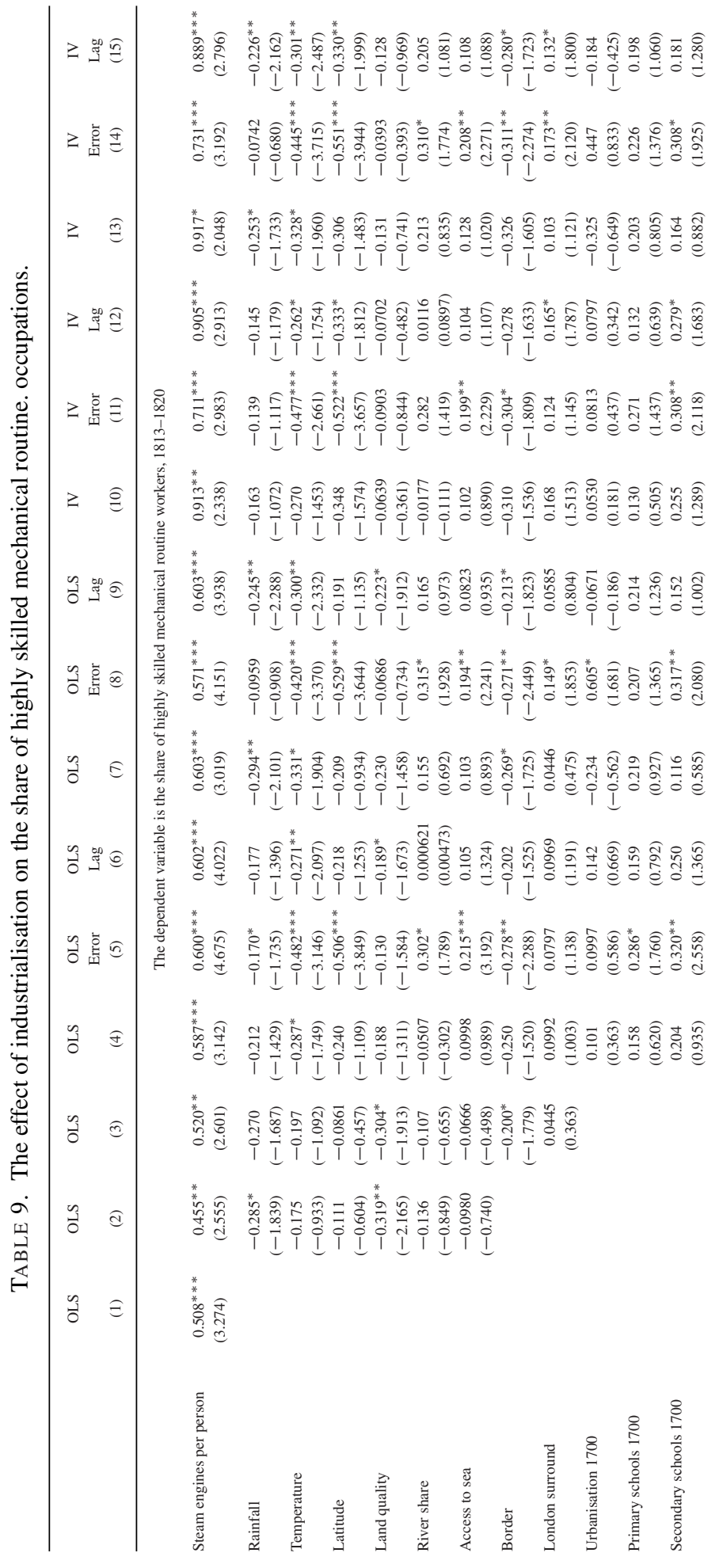




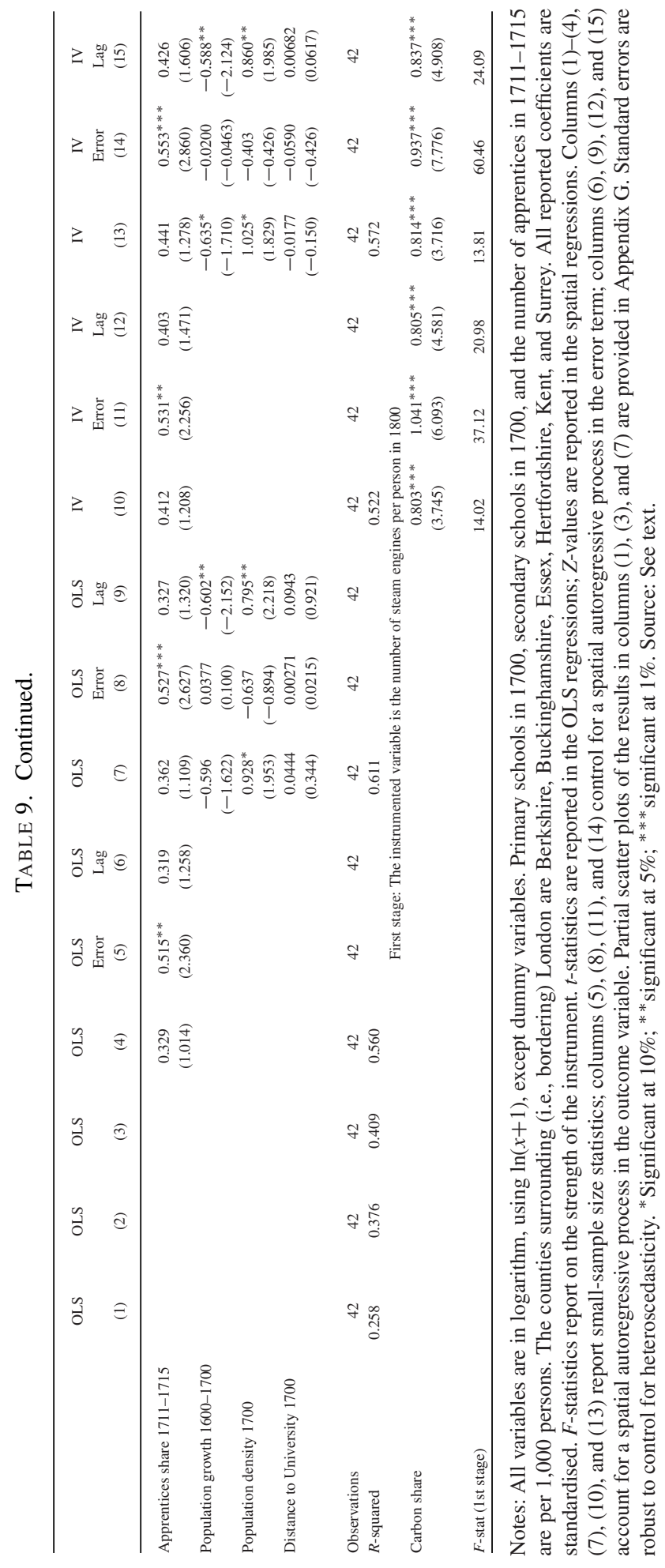




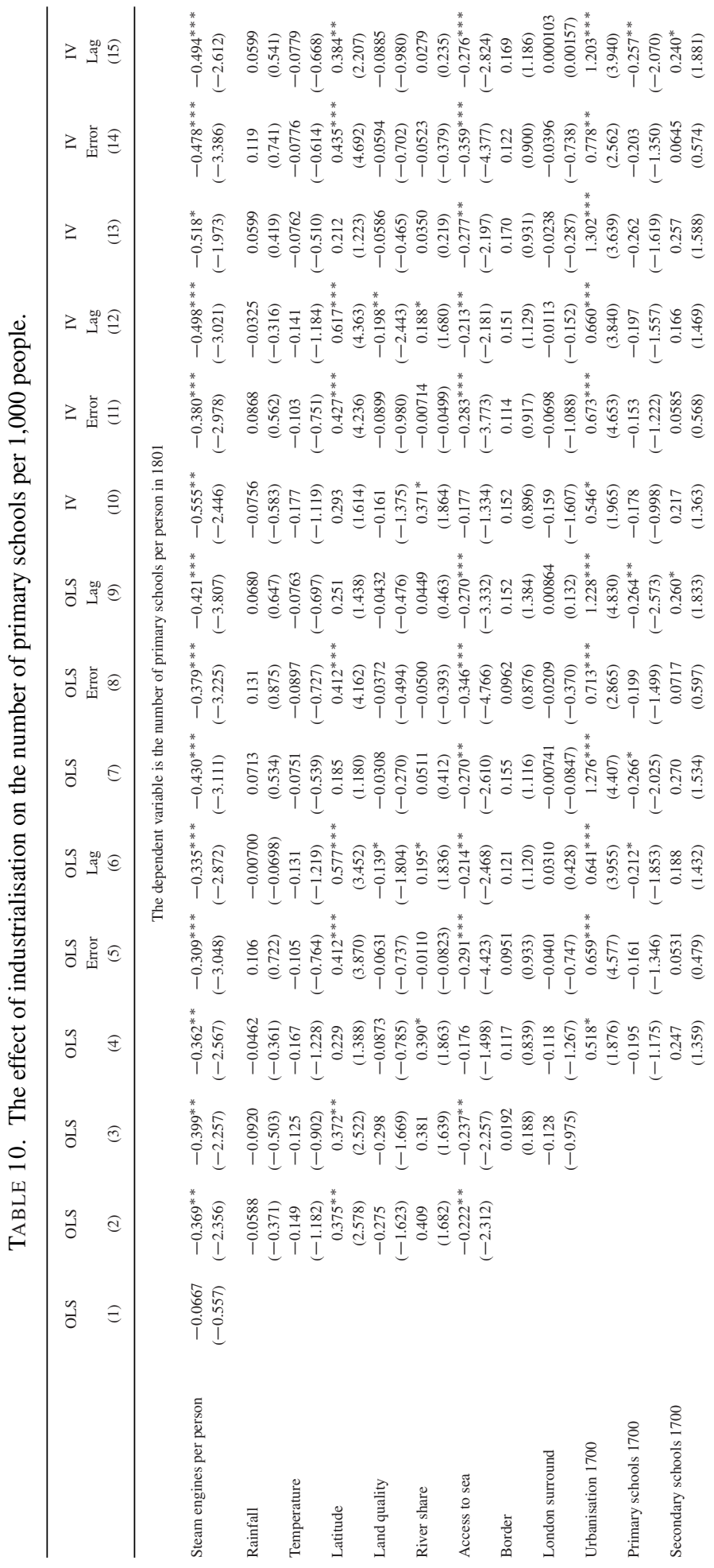




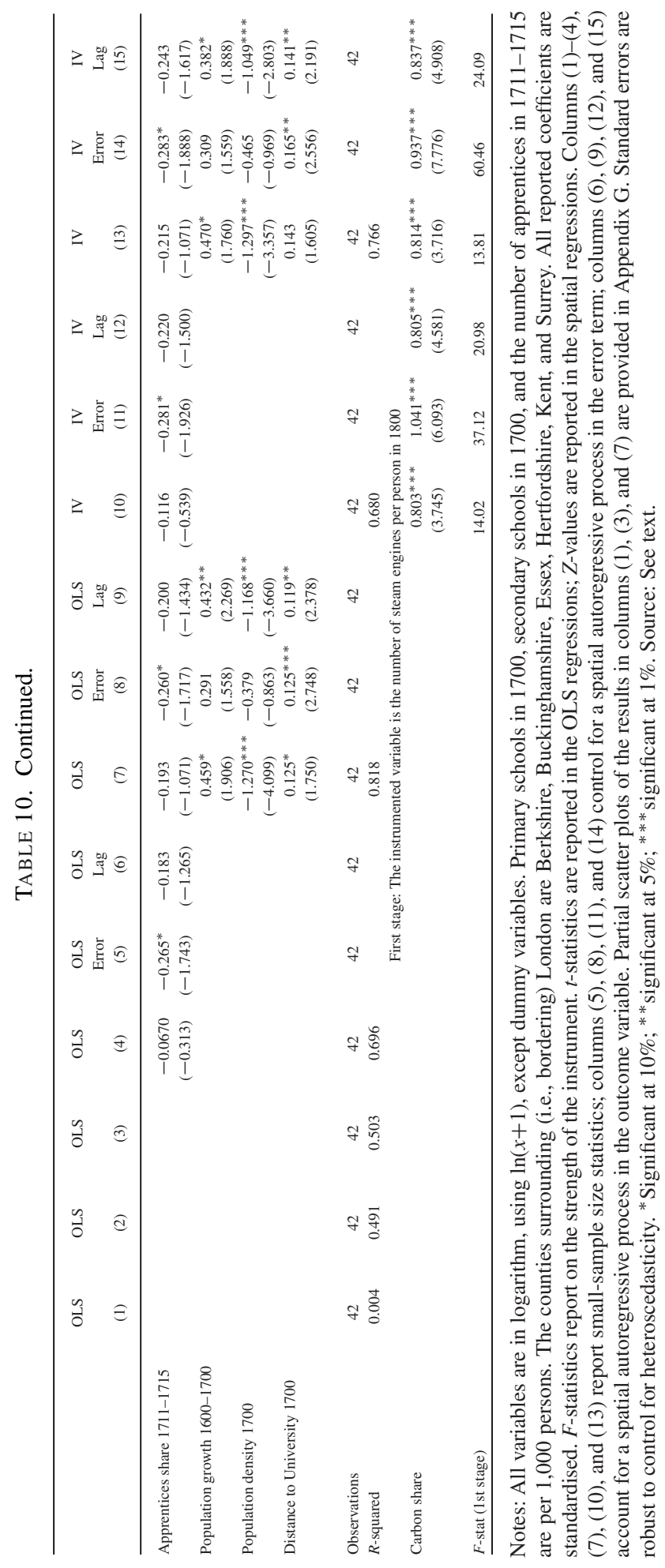




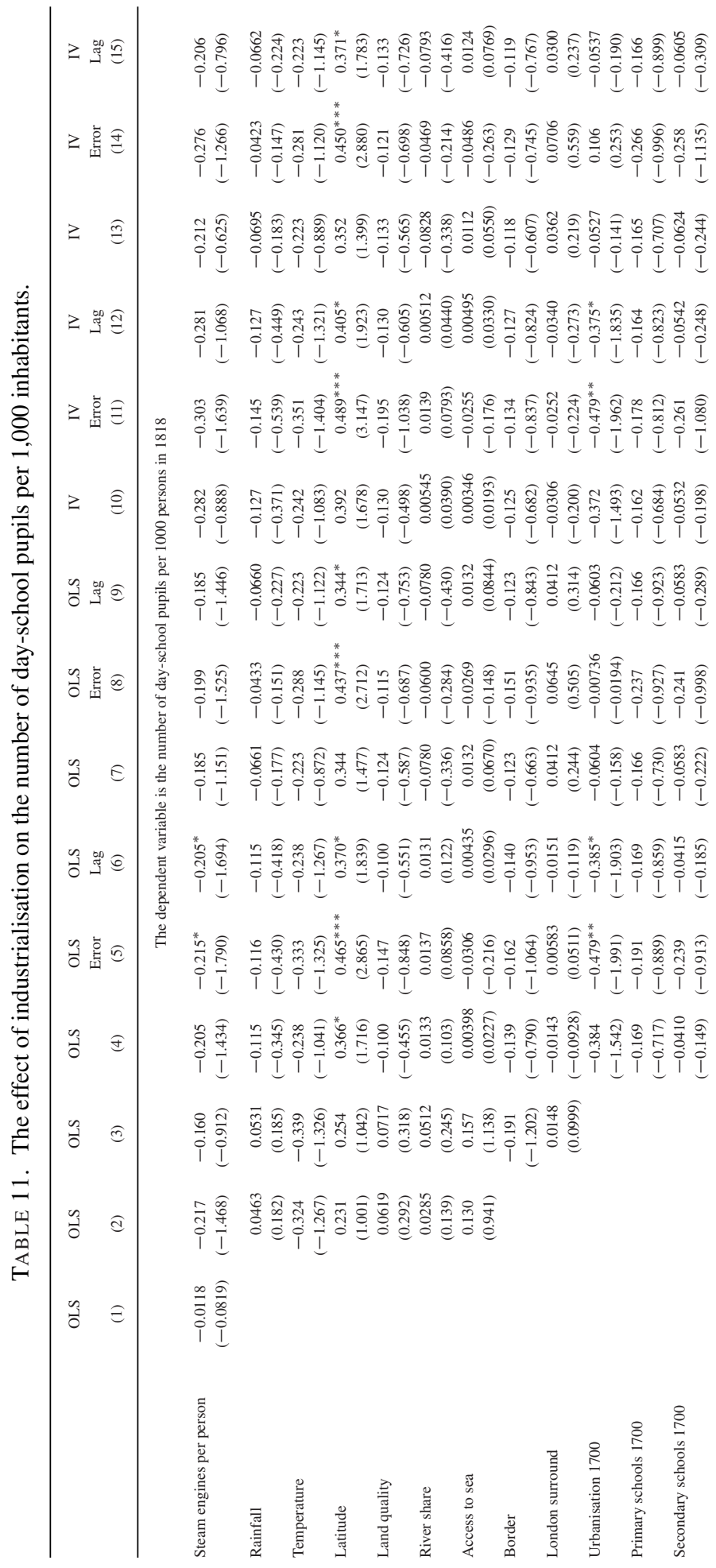




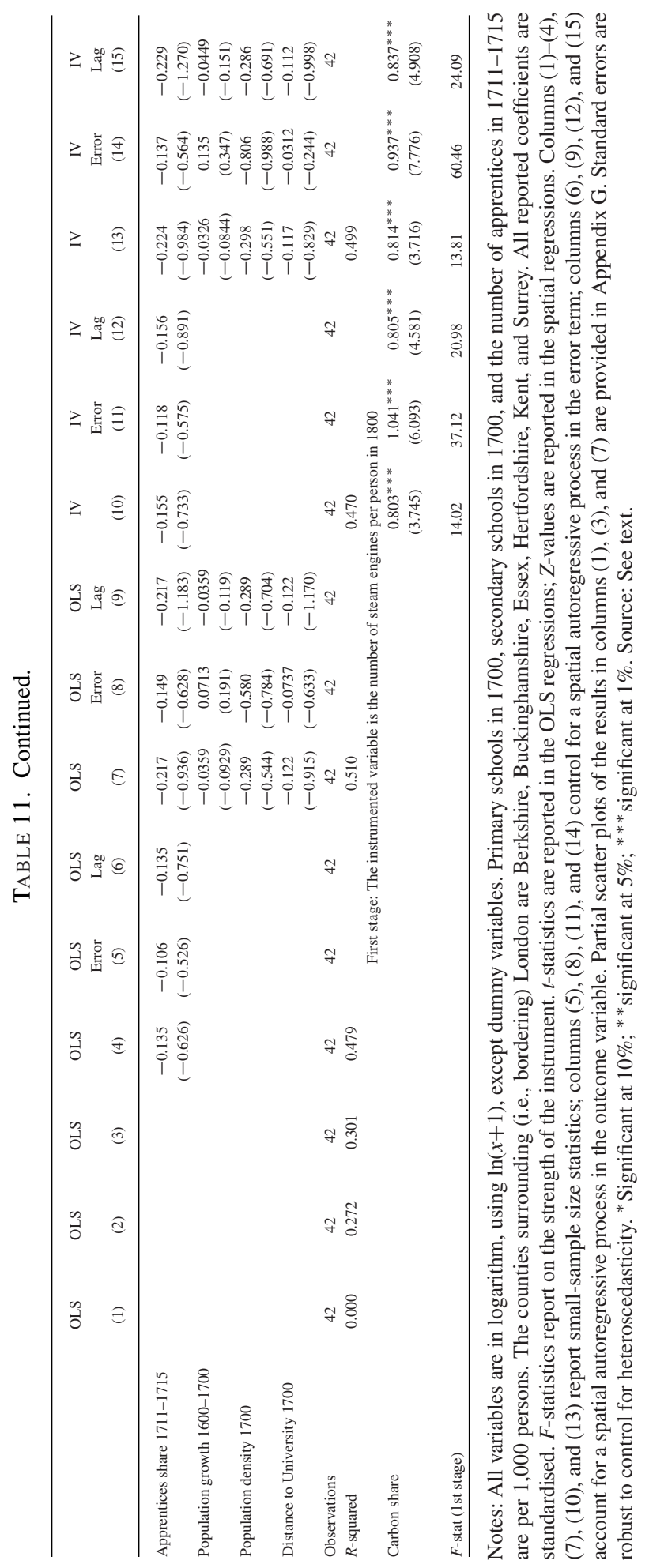


Tables 12 and 13 report the relationships between steam use and male and female literacy attainments. As with day-school rates, the effect of steam on male literary rates is generally negative, but not statistically significant at the $10 \%$ level (Table 12). Contrary to males, there is a strong economically and statistically significant negative effect of steam on female literacy rates (Table 13). Moreover, Table 14 shows the results of regressing gender inequality in literacy, that is, the difference between the male and female literacy rates relative to the male literacy rate, on the steam engines per person. The table establishes a large and positive effect of steam on how well males perform relative to females. From zero engines to number of steam engines per 1,000 persons in Yorkshire West Riding's would have caused female literacy to decline by 8 percentage-points and gender inequality in literacy to increase by 11 percentage-points (relative to sample means of $53 \%$ and $18 \%$, respectively).

Overall the analyses of the effects of new industrial technology on literacy, as well as schools and school enrolment rates, gives the impression that technological progress had a negative influence on the formation of basic educational skills. These findings chime with the earlier analysis of Humphries (2010) showing that industrialisation led to a decrease in average years of schooling. They also correspond with previous work that has found a stagnant male literacy rate during the classic period of the Industrial Revolution (e.g., Schofield 1973; Nicholas and Nicholas 1992; Mitch 1999).

Perhaps the most detailed support for the findings observed in Tables 10-14 is provided in Sanderson's (1972) study of England's industrial counties. Sanderson found that population increase was slower than growth in the number of schools during the first half of the 18th century, which meant more schools per person. However, during the latter half of the 18th century, when steam technology spread rapidly, Sanderson observed that the reverse was true. In actual numbers, Sanderson (1972, p. 77) asserts that the population in England's industrial areas rose by $126 \%$ between 1750 and 1800 , whereas the number of schools only rose by $20 \%$. This meant that population per school increased noticeably in the regions examined by Sanderson-from 2,305 to 3,845 people per school. The developments Sanderson described could well explain the observed effects concerning school enrolment rates (Tables 10 and 11). The decline in school performance rates is thus not necessarily caused by the lack of a wage premium for basic education. They could equally well be an outcome of the massive inflow of people to England's emerging industrial centres, causing a lack of access to education. In the latter interpretation, the introduction and use of steam technology has an indirect negative effect on schooling caused via migration. This would be a topic subject to further examination in future work, as our data do not enable us to explore the role of migration.

Regarding the observed gendered effects reported in Table 14, Sanderson also found very low rates of literacy - typically less than 10\% - for women employed in typical early-industry professions such as power-loom weavers, rovers, wheelers, and carders (Sanderson 1972, p. 90). This was much lower than the literacy rate among identical male occupations, which was usually around 35\%. Sanderson also observed a gap in literacy between industrial and agricultural female employees. He found that women in traditional, rural occupations, such as servants, had literacy rates of over 40\%. Sanderson's findings are thus consistent with our estimates reported in Tables 12 


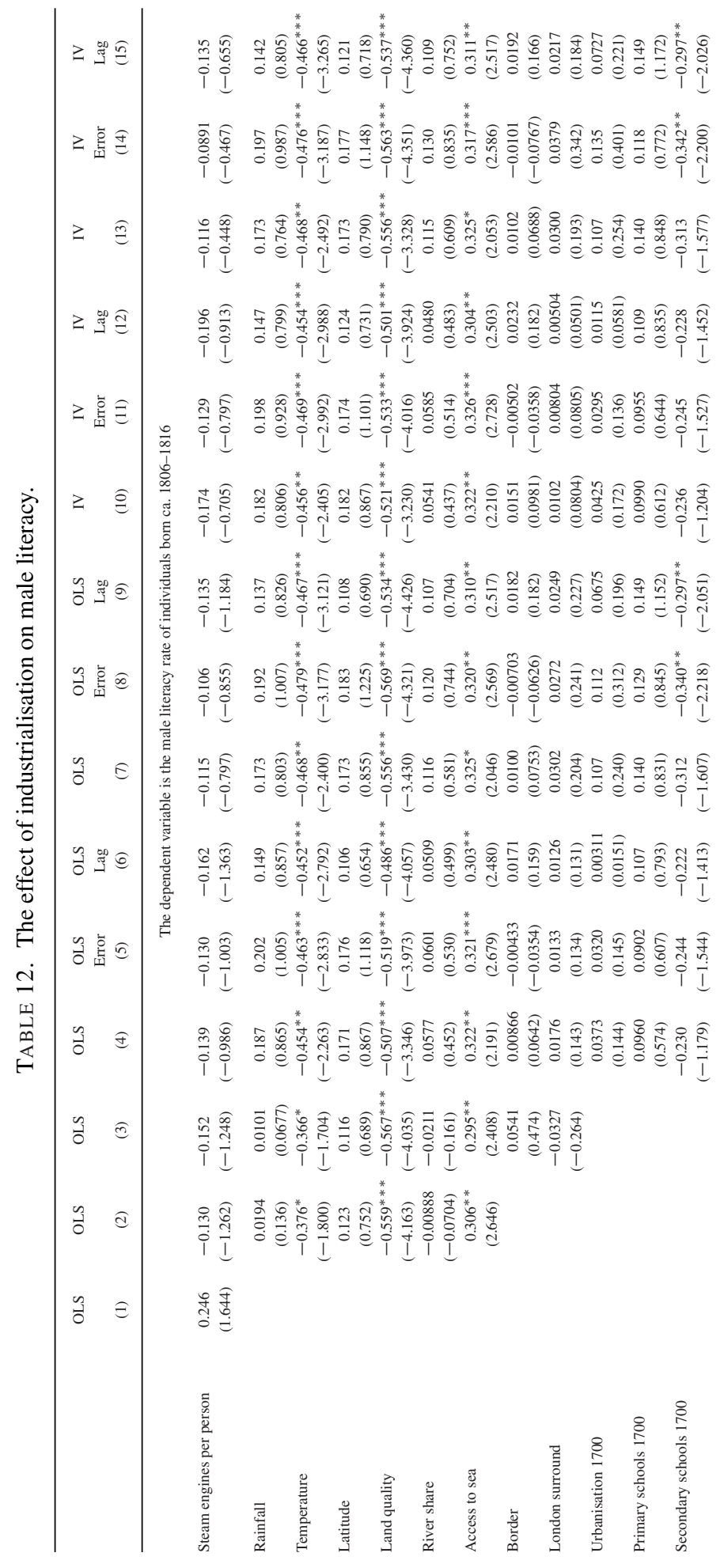




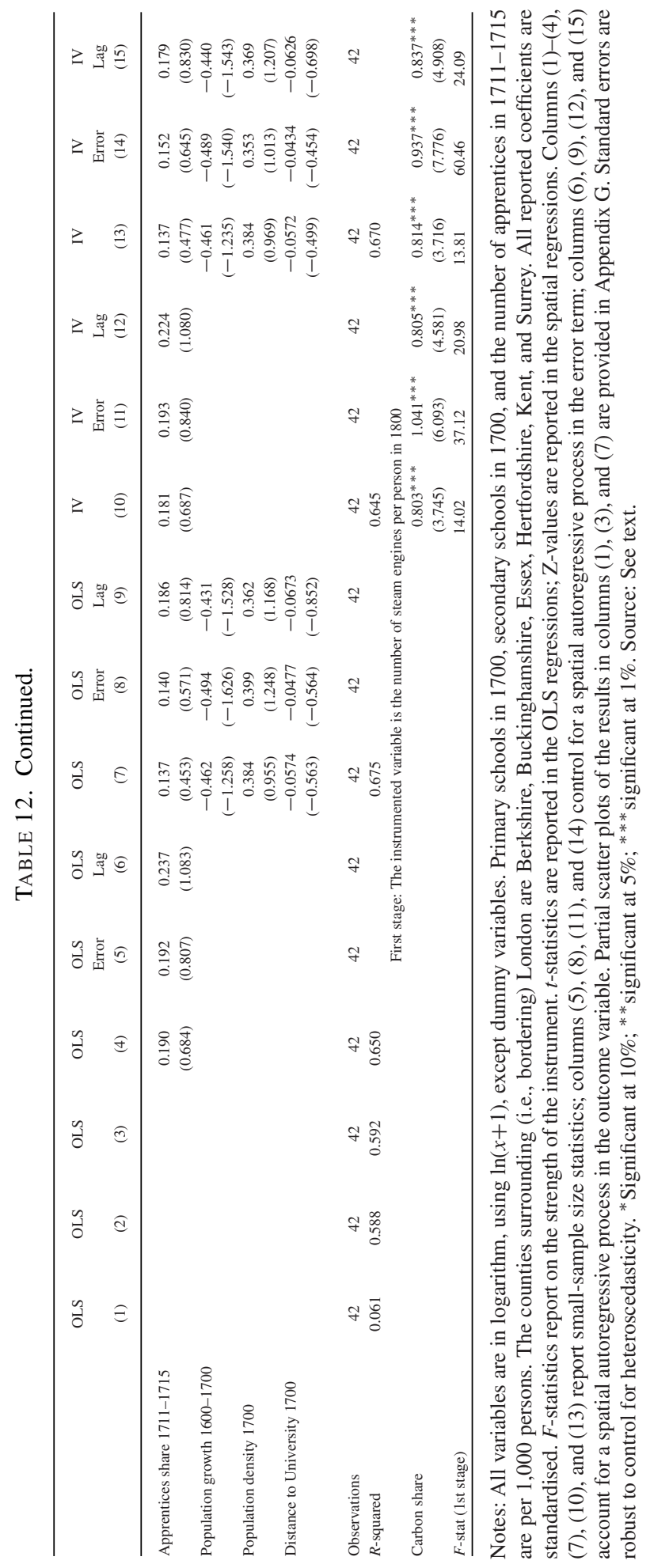




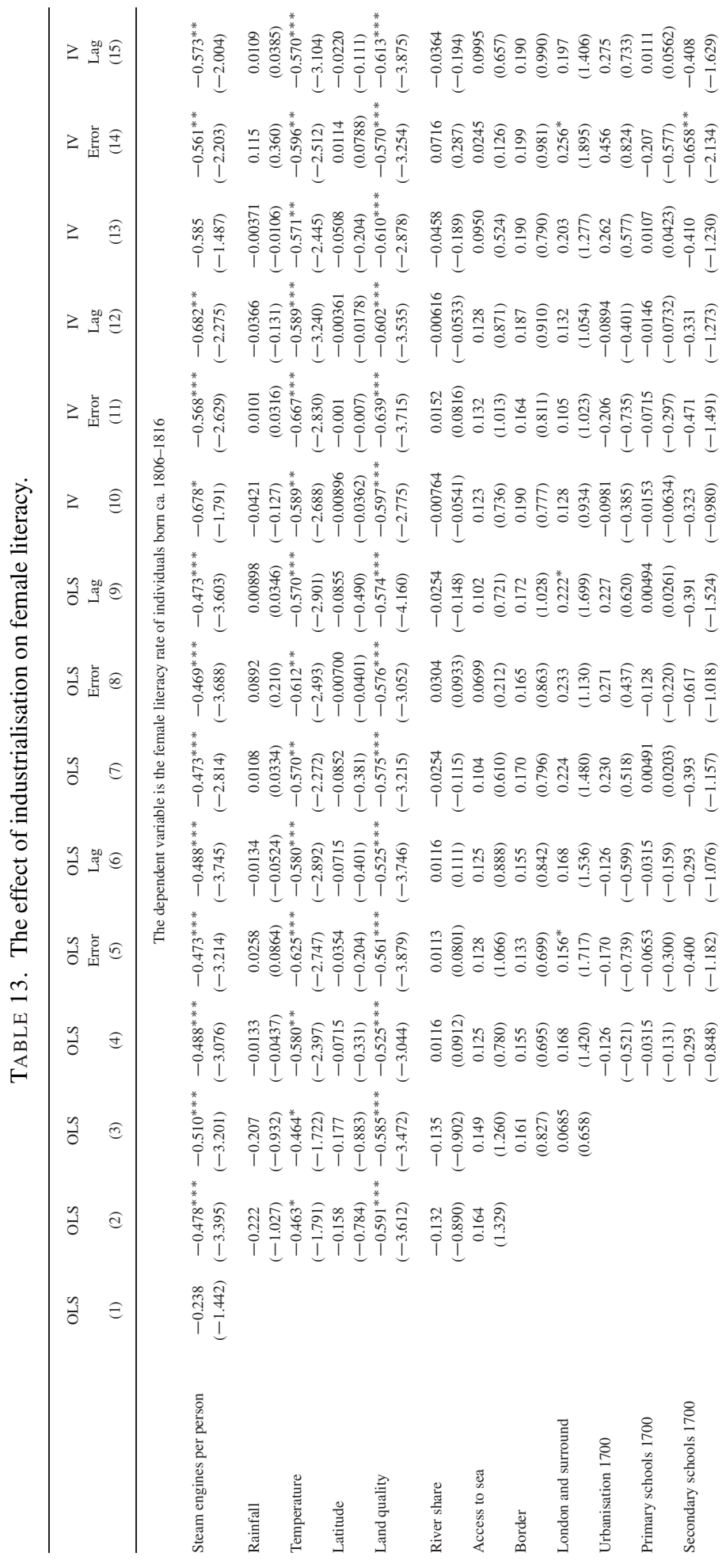




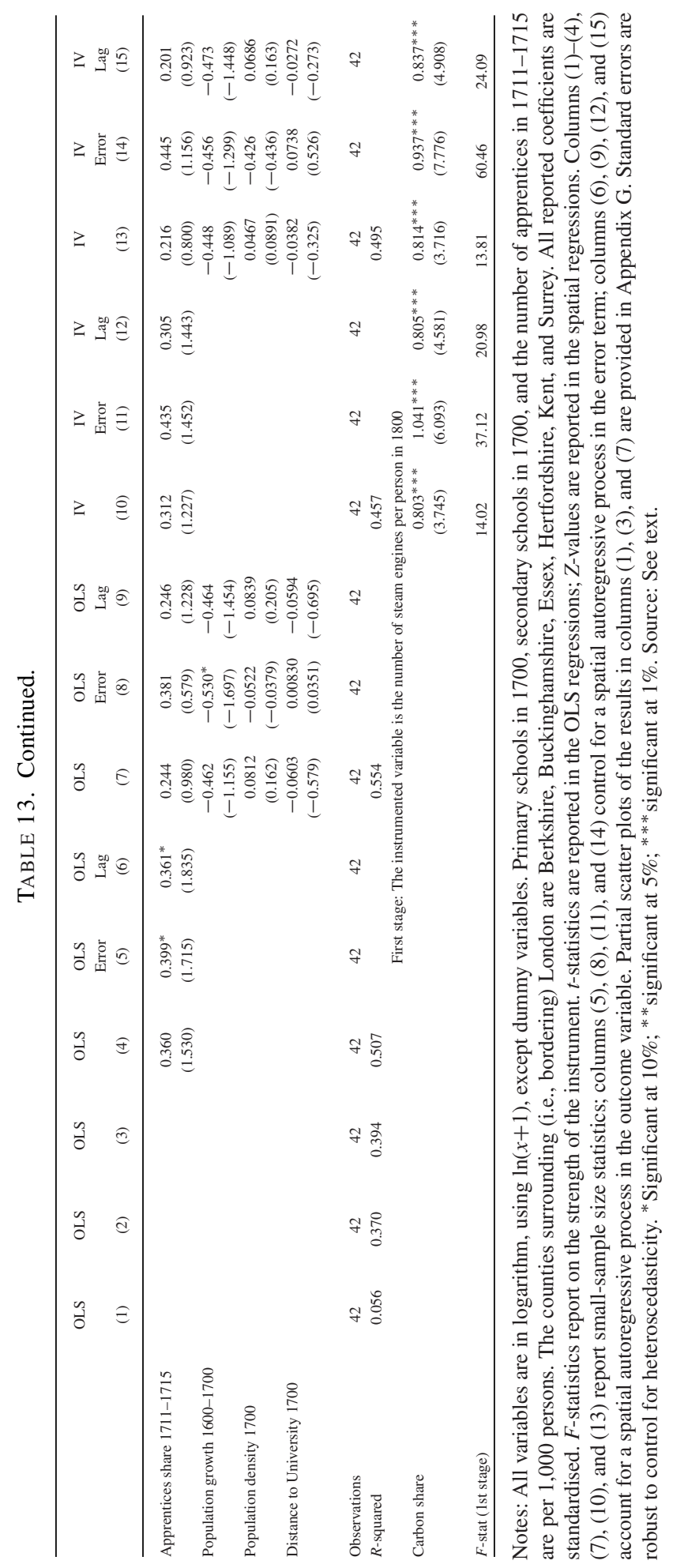




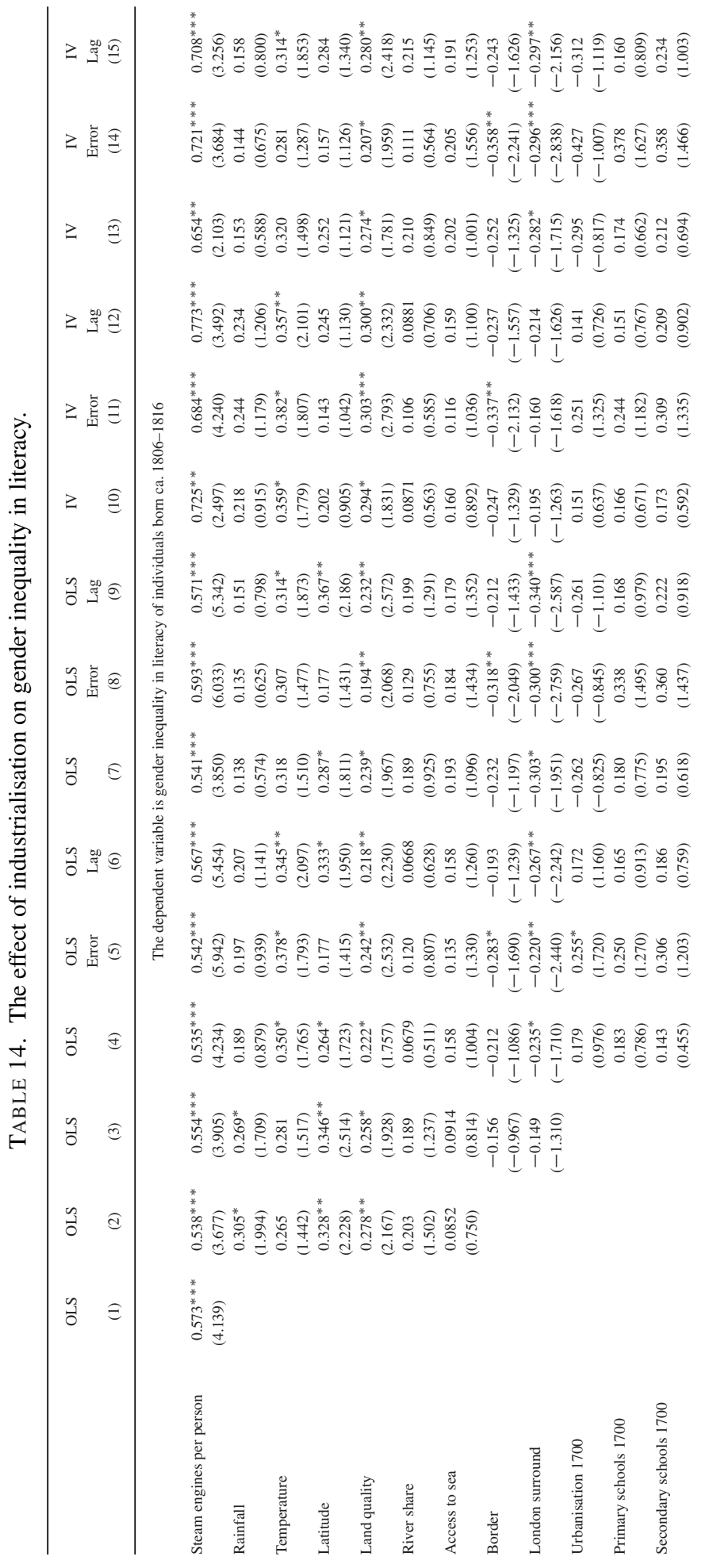




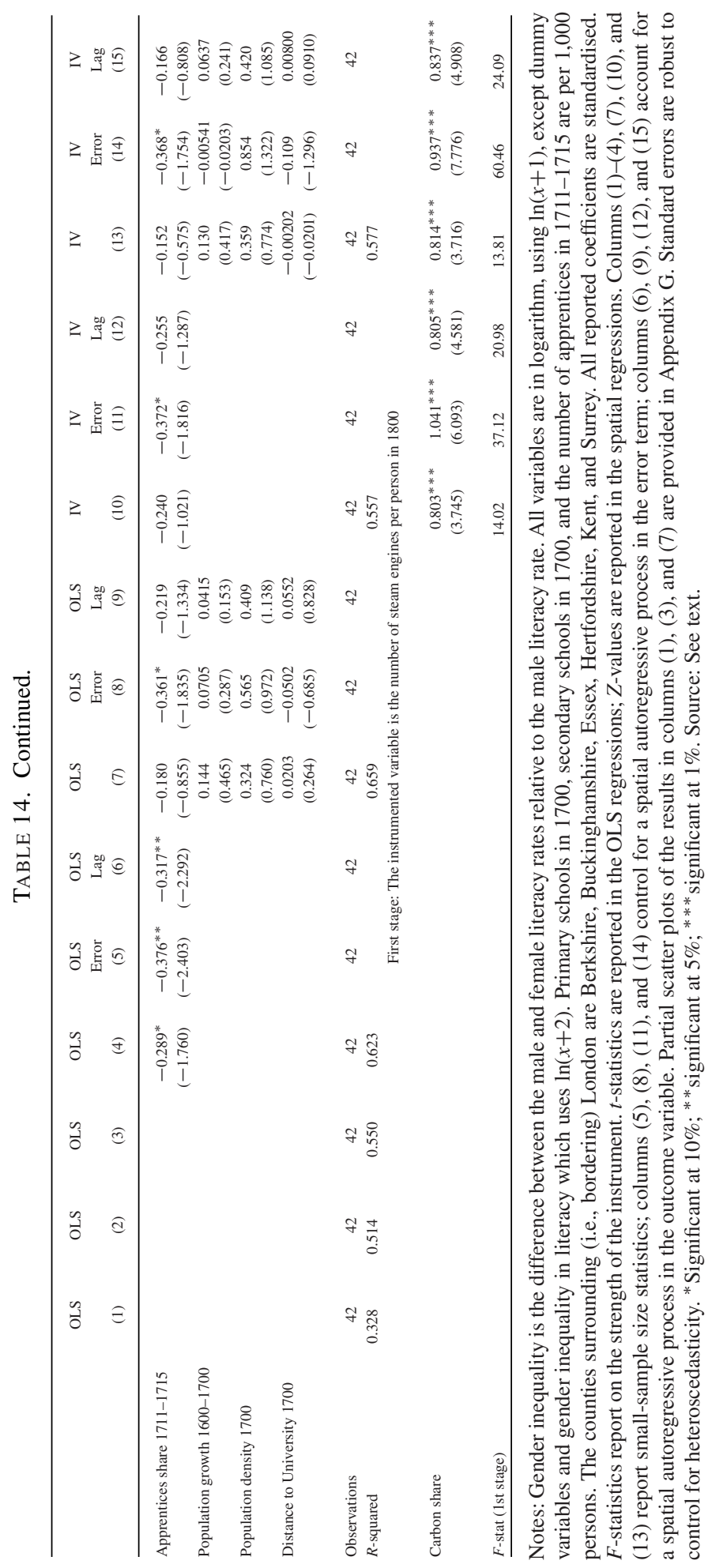


and 13, which suggest that literacy was less common among women employed in the emerging factories than in traditional agriculture.

In summary, early industry in England, as captured by the number of steam engines per person installed by 1800 , had a positive effect on the formation of working skills, but an overall negative effect on the formation of basic schooling skills, including literacy and school enrolment rates, and moreover a negative effect on gender inequality in literacy.

\section{Robustness Checks}

This section explores the robustness of the baseline analyses conducted previously. We begin by examining the role of time with regards to access to steam technology, and then consider whether or not the steam engines used in mining were the main driver of our baseline results. Furthermore, although our baseline analyses dealt mainly with confounding factors to be considered exogenous in the process of the Industrial Revolution, such as geography, our robustness analyses in what follows deal also with variables that might have been endogenous in this process, such as the availability of raw materials and the prevalence of various mills. Last, because the size of our sample is relatively modest, we also perform Jack-knife regressions to make sure that our baseline results were not driven by outliers.

\subsection{The Time Dimension of The Adoption of Steam Technology}

Did the fact that some counties adopted steam technology earlier than others play a role for their human capital formation? To find out, we examine the impact of a county's time with steam, which we call the steam history of county $i$. For this, we use the following formula:

$$
\text { Steam history }_{i}=\sum_{t=1702}^{1800} E_{t}(1801-t),
$$

where $E_{t}$ is the number of engines installed at time $t$, with $t$ ranging between 1702 when the first engine was put to use and 1800 when our period of observation ends. In this way, an engine is given more weight the earlier it was installed. The steam-history index varies between 0 (for counties without steam engines) and 5,051 (for Northumberland which had 186 steam engines in 1800). Table H.1 in the Online Appendix H summarises the findings using the (log of) the steam-history index deflated by population levels in 1800 as the main independent variable. The baseline conclusions are robust to this steam-use re-specification.

Interestingly, comparing the magnitudes of Table H.1 in the Online Appendix H to those of Table 8 reveals that the effect of steam on the shares of mechanical nonroutine workers are larger when time with steam is taken into account. If a county with no steam increased its number of steam engines per 1,000 persons to the level of 
Derbyshire, another important industrial centre with a steam-history index of 10 per 1,000 persons, ${ }^{15}$ then it would have led to a 3 percentage-points increase in the share of mechanical non-routine workers (relative to a sample mean of 5\%). The baseline effect was nearly half the size, that is, 1.6 percentage-points.

Overall, our findings suggest that counties where steam engines were introduced earlier had a higher accumulation of work-specific human capital and a lower formation of basic educational competencies, thus confirming the baseline results described previously.

\subsection{Non-Mining Engines}

The number of steam engines used in the previous baseline regressions includes engines that were operating both in mining and non-mining activities. Some of the mining engines were used to pump water out of the mines, that is, an activity not necessarily associated with the Industrial Revolution. In order to account for this, we can examine the effect of the number of non-mining engines per 1,000 people instead. Although the $F$-statistics in some cases drop below the habitual weak-instruments cut-off level (i.e., 10), Table H.2 in the Online Appendix H nevertheless confirms the baseline results. Indeed, many coefficients are numerically larger and statistically more significant when steam engines used in mining are excluded. For example, the effect of introducing nonmining steam engines is a 19 percentage-points decline in the share unskilled workers against a baseline effect of 13 percentage-points.

\subsection{Raw Materials}

The presence of raw materials, such as iron, could have influenced the location and therefore concentration of steam engines. Moreover, the wealth generated by the presence of raw materials could have helped pay for the formation of human capital. We therefore repeat the baseline regression analyses reported in Section 3 with and without controlling for the county-level distribution of blast furnaces per 1,000 persons, capturing the tendency to use iron, an important raw material in production, across the English counties. ${ }^{16}$ Tables I.1-I.3 in the Online Appendix I repeat the analysis reported in columns (13)-(15) of Tables 3-14. The results show that the coefficient on the number of steam engines per person hardly changes when controlling for the prevalence of the blast furnaces.

\subsection{Religion}

The occupational data used to construct the shares of working skills by county come from Anglican Church registers. The Anglican Church was the dominant religious institution in England at the time. However, since other religious groups-for example,

15. Similar to Yorkshire West Riding, Derbyshire is found on the 85th percentile.

16. The entry for London is made equal to Middlesex. 
Catholics, Orthodox Christians, and Jews-co-existed and could have had different views regarding the importance of human capital, these groups may have influenced the formation of human capital and wealth which helped industrialisation. There are good historical records to inform us about the intensity of various religions across the English counties. Mann's (1854) study of how church seats were divided in 1851 within each county between the different religious groups can help inform us whether or not differences in the share of Anglicans were important to human capital. ${ }^{17}$ Tables I.4-I.6 in the Online Appendix I show that the baseline results are robust.

\subsection{Mills}

Steam engines were not the only source of mechanical power present in England at the time. Cotton-, wool-, and water-mills also played an important role, not just during the Industrial Revolution, but also earlier. Again, we replicate the baseline regressions reported in Section 3 with and without controlling for the county-level numbers of cotton-, wool-, and water mills per 1,000 persons used in 1800. Tables I.7-I.9 in the Online Appendix I repeat the analysis of columns (13)-(15) in Tables 3-14. ${ }^{18}$ The baseline results are robust.

\subsection{Jack-Knife Regressions}

Our dataset looks at a cross-section containing 42 observations. This means that outliers could potentially drive our results. In order to examine whether or not this is the case, we replicated the previous baseline analyses using a Jack-knife estimation technique. Tables J.1-J.2 in the Online Appendix I replicate columns (10)-(13) of Tables 3-14, showing the coefficient on steam engines per person when leaving out one county at the time. The baseline results are robust. ${ }^{19}$

\section{Conclusion}

Economic historians have traditionally regarded the process of technological change during England's Industrial Revolution as inherently de-skilling. Indeed, new technologies, including steam engines, are said to have been introduced with the specific aim to substitute or “dilute" workers' skills, as argued in Berg (1980, 1994) and elsewhere. This view has recently been challenged in a number of studies,

17. The share of Anglicans in Hampshire is the average of the neighbouring counties, that is, Dorset, Wiltshire, Berkshire, Surrey, and Sussex. The value for London is made equal to Middlesex.

18. The number of mills in London is made equal to Middlesex.

19. Please note that these regressions do not enable us to control for spatial autocorrelation. The $t$-statistics may therefore be slightly biased downwards. 
notably in Franck and Galor (2017), which shows that the Industrial Revolution in France was skill-demanding, and in Meisenzahl and Mokyr (2012) and Feldman and van der Beek (2016), which argue that the introduction of new technologies during England's Industrial Revolution led to the creation and consolidation of new working skills. Those new working skills were held not only to be needed for the production and instalment of new machines, but also in order to operate and maintain them.

Inspired by these studies, this paper has carried out a systematic quantitative assessment of the effect of industrialisation, captured by the number of steam engines per person installed in England by 1800, on the average working skills of the workforce at the time. We obtained several measures of working skills by exploiting the skillcontent of more than 2.6 million workers' jobs, finding support for the notion that England's Industrial Revolution was skill-demanding on average and that the effect was causal.

We also tested the impact of industrialisation on a number of measures of more basic human capital formation, finding that early industrialisation was generally negatively associated with primary schooling and with the acquisition of literacy skills for women. Industrialisation also exercised a negative influence on gender inequality in literacy. These findings agree with Sanderson's (1972) observation that female industrial employees had markedly lower rates of literacy, both compared with their female agricultural counterparts and with their male industrial peers. The lack of a statistically significant negative effect of industrialisation on the attainment of male literacy is consistent with previous observations in Nicholas and Nicholas (1992), who detected a pause in the growth in English male literacy rates during the Industrial Revolution. Overall, our findings tend to confirm Mokyr's (2005) conclusion that basic education was not a key ingredient in England's early industrialisation.

One of the key hypotheses about the effect of technological change on the formation of human capital during early industrialisation is the workshop-to-factory argument. According to this hypothesis, products that were previous produced by skilled artisans started to be manufactured in factories by workers with relatively few skills, thus reducing the demand for skilled workers (James and Skinner 1985; Goldin and Katz 1998; Acemoglu 2002). Skilled artisans reacted by destroying the factory machines they believed would render their skills redundant, a phenomenon connected with the Luddites riots (Nuvolari 2002). In the absence of individual, time-varying occupational information, we are unable to test this hypothesis formally. Hence, we cannot confirm or rule out that idle artisans had to seek employment as lower- or unskilled workers in the emerging factories.

However, an additional, and possibly competing, hypothesis, and one that is more plausibly in line with what we observe previously, is that the emerging factories recruited mainly from the pool of unskilled agricultural workers. This supposition means that the concentration of skills in England's steam-intensive areas 
came from "upgrading" unskilled agricultural labourers to lower- and mediumskilled manufacturing workers. This is not to say that the workshop-to-factory argument is invalid, but rather that it arguably concerned a much more modest pond of medium-skilled craftsmen compared to the masses of unskilled agricultural workers that could be drawn from the lowest segments of the skill ladder. Of course, unskilled agricultural workers' advancement into lower- or medium-skilled occupations would not necessarily have emerged through primary schooling, such as the acquisition of reading and writing skills, but more likely via work-specific training on the job. ${ }^{20}$ Contrary to the traditional workshop-to-factory argument of medium-skilled workers' downward mobility, we thus conjecture, based on our findings, that early industrialisation prompted a farmwork-to-factory transition, whereby unskilled agricultural workers experienced upward mobility instead. Not only would this transition help explain migration from rural to urban areas at the time. The upgrading hypothesis is also more in tune with the broader consensus based on 20th-century evidence that technological change favours skills (Acemoglu 2002). However, further research is needed to confirm or reject this hypothesis.

20. According to HISCLASS, unskilled work required less than 30 days of training, whereas lowerskilled work required between 30 days and one year of training (see Table D.1 in the Online Appendix D and Maas and van Leeuwen 2011, Table 4.3). For example, a "spinner" needed more than 30 days of training and is deemed lower-skilled in HISCLASS, whereas a "farm worker" needed less than 30 days of training and is deemed unskilled in HISCLASS. 


\section{Appendix A}

Table A.1. Descriptive statistics.

\begin{tabular}{|c|c|c|c|c|c|}
\hline & Obs. & Mean & Std. Dev. & Min. & Max. \\
\hline \multicolumn{6}{|l|}{ Dependent variables } \\
\hline Share of unskilled workers, $1813-1820$ & 42 & 0.42 & 0.14 & 0.13 & 0.63 \\
\hline Share of lower-skilled workers, 1813-1820 & 42 & 0.19 & 0.11 & 0.07 & 0.51 \\
\hline Share of medium-skilled workers, $1813-1820$ & 42 & 0.37 & 0.06 & 0.29 & 0.55 \\
\hline Share of highly-skilled workers, 1813-1820 & 42 & 0.02 & 0.01 & 0.01 & 0.03 \\
\hline Share of skilled workers in industry, $1813-1820$ & 42 & 0.33 & 0.11 & 0.20 & 0.63 \\
\hline Share of mechanical non-routine workers, $1813-1820$ & 42 & 0.05 & 0.02 & 0.03 & 0.14 \\
\hline Share of mechanical routine workers, $1813-1820$ & 42 & 0.10 & 0.03 & 0.07 & 0.20 \\
\hline Number of primary schools per 1,000 people in 1801 & 42 & 0.47 & 0.40 & 0.07 & 2.56 \\
\hline Day-school scholars per 1,000 people in 1818 & 42 & 7.46 & 1.90 & 4.10 & 13.20 \\
\hline Male literacy rate of individuals born c. 1806-1816 & 42 & 0.65 & 0.09 & 0.50 & 0.84 \\
\hline Female literacy rate of individuals born c. 1806-1816 & 42 & 0.53 & 0.09 & 0.33 & 0.72 \\
\hline Gender inequality in literacy of individuals born c. $1806-1816$ & 42 & 0.18 & 0.10 & -0.07 & 0.47 \\
\hline \multicolumn{6}{|l|}{ Main independent variable } \\
\hline Number of steam engines per 1,000 people in 1800 & 42 & 0.18 & 0.28 & 0.00 & 1.13 \\
\hline \multicolumn{6}{|l|}{ Instrumental variable } \\
\hline Share of county's area covered by carboniferous rock strata & 42 & 0.15 & 0.24 & 0.00 & 0.84 \\
\hline \multicolumn{6}{|l|}{ Control variables } \\
\hline Latitude $(1,000 \mathrm{~km})$ & 42 & 52.38 & 1.24 & 50.26 & 55.41 \\
\hline Access to sea (maritime) & 42 & 0.45 & 0.50 & 0.00 & 1.00 \\
\hline Border shared with Scotland or Wales & 42 & 0.14 & 0.35 & 0.00 & 1.00 \\
\hline London and surroundings & 42 & 0.17 & 0.38 & 0.00 & 1.00 \\
\hline Average rainfall $(\mathrm{mm})$ & 42 & 690.68 & 122.39 & 549.90 & 1232.00 \\
\hline Average temperature (Celsius) & 42 & 10.11 & 0.95 & 7.75 & 12.50 \\
\hline Share of county's area covered by waterways & 42 & 0.12 & 0.04 & 0.00 & 0.22 \\
\hline Quality of agricultural land & 42 & 0.17 & 0.16 & 0.00 & 0.73 \\
\hline Number of apprentices per 1,000 people, $1711-15$ & 42 & 0.72 & 0.67 & 0.15 & 3.38 \\
\hline Urbanisation rate in 1700 & 42 & 0.09 & 0.21 & 0.00 & 0.99 \\
\hline Number of secondary schools per 1,000 people in 1700 & 42 & 0.13 & 0.08 & 0.01 & 0.48 \\
\hline Number of primary schools per 1,000 people in 1700 & 42 & 0.11 & 0.07 & 0.00 & 0.28 \\
\hline Aerial distance to nearest University $(1,000 \mathrm{~km})$ & 42 & 100.68 & 58.93 & 1.00 & 290.38 \\
\hline Population growth rates between 1600 and 1700 & 42 & 0.26 & 0.28 & -0.10 & 1.88 \\
\hline Population density in 1700 (people per 1,000 km²) & 42 & 9,063 & 58,393 & 18.72 & 378,481 \\
\hline \multicolumn{6}{|l|}{ Variables for robustness analyses } \\
\hline Steam history per 1,000 people in 1800 & 42 & 3.84 & 6.96 & 0.00 & 30.72 \\
\hline Number of non-mining engines per 1,000 people in 1800 & 42 & 0.06 & 0.10 & 0.00 & 0.48 \\
\hline Number of blast furnaces per 1,000 people in 1800 & 42 & 0.01 & 0.03 & 0.00 & 0.14 \\
\hline Number of cotton mills per 1,000 people in 1800 & 42 & 0.03 & 0.09 & 0.00 & 0.38 \\
\hline Number of wool mills per 1,000 people in 1800 & 42 & 0.06 & 0.13 & 0.00 & 0.70 \\
\hline Number of water mills per 1,000 people in 1800 & 42 & 0.91 & 0.76 & 0.09 & 4.80 \\
\hline Share of Anglicans church seats & 42 & 0.56 & 0.09 & 0.37 & 0.72 \\
\hline
\end{tabular}

Source: See text. 


\section{References}

Acemoglu, Daron (2002). "Technical Change, Inequality, and the Labor Market." Journal of Economic Literature, 60, 7-72.

Allen, Robert C. (2009). The British Industrial Revolution in Global Perspective. Cambridge University Press.

Andersen, Thomas B., Jeanet Bentzen, Carl-Johan Dalgaard, and Paul Sharp (2017). "PreReformation Roots of the Protestant Ethic.” The Economic Journal, 127, 1756-1793.

Asch, Kristine (2005). "The 1:5 Million International Geological Map of Europe and Adjacent Areas." German Federal Institute for Geoscience and Natural Resources. BGR, Hannover, Germany.

Atack, Jeremy, Fred Bateman, and Robert A. Margo (2004). "Skill Intensity and Rising Wage Dispersion in Nineteenth-Century American Manufacturing." Journal of Economic History, 64, 172-192.

Atack, Jeremy, Fred Bateman, and Robert A. Margo (2008). "Steam Power, Establishment Size, and Labor Productivity Growth in Nineteenth Century American Manufacturing." Explorations in Economic History, 45, 185-198.

Baten, Joerg, Dorothee Crayen, and Hans-Joachim Voth (2014). "Numeracy and the Impact of High Food Prices in Industrializing Britain, 1780-1850." Review of Economics and Statistics, 96, 418-430.

Bosker, Maarten, Eltjo Buringh, and Jan Luiten van Zanden (2013). "From Baghdad to London: Unraveling Urban Development in Europe, the Middle East, and North Africa, 800-1800." Review of Economics and Statistics, 96, 1418-1437.

Berg, Maxine (1980). The Machinery Question and the Making of Political Economy 1815-1848. Cambridge University Press.

Berg, Maxine (1994). The Age of Manufactures. Industry, Innovation and Work in Britain, 1700-1820. Routledge.

Census of Great Britain (1841). 1841 Abstracts of the Answers and Returns made pursuant to Acts 3 \& 4 Vict. C. 99, and 4 Vict. C. 7, intituled respectively "An Act "for taking an Account of the Population of Great Britain," and "An Act to amend the Acts of the last Session for taking an Account of the Population." Enumeration Abstract, 1841. Part I England and Wales and Islands in the British Seas. (1843 xxii (496) 1).

Cinnirella, Francesco, Marc Klemp, and Jacob L. Weisdorf (2017). "Malthus in the Bedroom: Birth Spacing as Birth Control in Pre-Transition England." Demography, 54, 413-436.

Clark, Gregory (2005). "Human Capital, Fertility, and the Industrial Revolution." Journal of the European Economic Association, 3, 505-515.

Crafts, Nicholas F. R. and Knick Harley (1992). "Output Growth and the British Industrial Revolution: A Restatement of the Crafts-Harley View." The Economic History Review, 45, 703-730.

Crafts, Nicholas F. R. and Abay Mulatu (2006). "How Did the Location of Industry Respond to Falling Transport Costs in Britain Before World War I?" Journal of Economic History, 66, 575-607.

Cullingford, C. C. (1980). A History of Dorset, Gloucestershire: History Press Limited.

De La Croix, David, Eric Schneider, and Jacob L. Weisdorf (2018). "Decessit sine prole: Childlessness, Celibacy, and Survival of the Richest." LSE Economic History Working Paper no. 276, London School of Economics and Political Science.

de Pleijt, Alexandra M. (2018). "Human Capital Formation in the Long Run: Evidence from Average Years of Schooling in England, 1300-1900.” Cliometrica, 12, 99-126.

de Pleijt, Alexandra M. and Jacob L. Weisdorf (2017). "Human Capital Formation from Occupations: The 'Deskilling Hypothesis' Revisited." Cliometrica, 11, 1-30.

Education Census (1851). Census of Great Britain, 1851, PP 1852-3, XC (reproduced in 1854), available at the British National Archives.

Engels, Friedrich (1993). The Condition of the Working Class in England. Oxford University Press (first edition published in 1845).

Feldman, Naomi E. and Karine van der Beek (2016). "Skill Choice and Skill Complementarity in Eighteenth Century England.” Explorations in Economic History, 59, 94-113.

Franck, Raphael and Oded Galor (2017). "Technology-Skill Complementarity in the Early Phase of Industrialization.” NBER Working Paper No. 23197, NBER, Cambridge, MA. 
Fernihough, Alan and Kevin H. O'Rourke (2014). "Coal and the European Industrial Revolution." NBER Working Paper No. 19802, NBER, Cambridge, MA.

Freeman, Christopher and Francisco Louca (2001). As Time Goes By. From the Industrial Revolutions to the Information Revolution. Oxford University Press.

Galor, Oded (2011). Unified Growth Theory. Princeton University Press.

Galor, Oded and David N. Weil (2000). "Population, Technology, and Growth: From Malthusian Stagnation to the Demographic Transition and Beyond." American Economic Review, 90, 806828.

Galor, Oded and Omer Moav (2006). "Das Human-Kapital: A Theory of the Demise of the Class Structure." Review of Economics Studies, 73, 85-117.

Galor, Oded, Omer Moav, and Dietrich Vollrath (2009). "Inequality in Landownership, the Emergence of Human-Capital Promoting Institutions, and the Great Divergence." Review of Economic Studies, 76, 143-179.

Goldin, C. and K. Sokoloff (1982). "Women, Children, and Industrialization in the Early Republic: Evidence from the Manufacturing Censuses." Journal of Economic History, 42, 741-74.

Goldin, Claudia and Lawrence F. Katz (1998). "The Origins of Technology-Skill Complementarity." The Quarterly Journal of Economics, 113, 693-732."

Griliches, Zvi (1969). "Capital-Skill Complementarity.” The Review of Economics and Statistics, 51, 465-468.

Humphries, Jane (2010). Childhood and Child Labour in the British Industrial Revolution. Cambridge University Press.

James, John A. and Jonathan S. Skinner (1985). "The Resolution of the Labor-Scarcity Paradox." Journal of Economic History, 45, 513-540.

Kanefsky, John W. and John Robey (1980). "Steam Engines in 18th-Century Britain: A Quantitative Assessment." Technology and Culture, 21, 161-186.

Katz, L. F. and R. A. Margo (2014). "Technical Change and the Relative Demand for Skilled Labor: The United States in Historical Perspective.” NBER Working Paper No. 18752.

Kitson, Peter M. (2013). "The Recording of Occupations in the Anglican Baptism Registers of England and Wales, 1690-1799." University of Cambridge, unpublished manuscript.

Lloyd-Jones, Roger and A. M. Le Roux (1980). “The Size of Firms in the Cotton Industry: Manchester 1815-41." Economic History Review, 33, 72-82.

Mann, Horace (1854). Census of Great Britain 1851: Religions Worship in England and Wales. George Routledge and Co.

Meisenzahl, Ralf and Joel Mokyr (2012). "The Rate and Direction of Invention in the British Industrial Revolution: Incentives and Institutions." In The Rate and Direction of Incentives and Institutions, NBER Books, pp. 443-479.

Minns, Christopher and Patrick Wallis (2013). "The Price of Human Capital in a Pre-industrial Economy: Premiums and Apprenticeship Contracts in $18^{\text {th }}$ Century England." Explorations in Economic History, 50, 335-350.

Mitch, David (1999). "The Role of Education and Skill in the British Industrial Revolution." In The British Industrial Revolution: An Economic Perspective, 2nd ed., edited by Joel Mokyr. New York: Routledge.

Mokyr, Joel (2005). "Long-Term Economic Growth and the History of Technology.” In The Handbook of Economic Growth, edited by Philippe Aghion and Steven N. Durlauf. Amsterdam: Elsevier.

Mokyr, Joel and Hans-Joachim Voth (2009). "Understanding Growth in Early Modern Europe." In The Cambridge Economic History of Europe, edited by Stephen N. Broadberry and Kevin H. O'Rourke. Cambridge University Press.

Nicholas, Stephen J. and Jacqueline M. Nicholas (1992). "Male Literacy, "Deskilling," and the Industrial Revolution." Journal of Interdisciplinary History, 23, 1-18.

Nuvolari, Alessandro (2002). "The "Machine-Breakers" and the Industrial Revolution." Journal of European Economic History, 31, 393-426.

Nuvolari, Alessandro, Bart Verspagen, and Nick von Tunzelmann (2011). "The Early Diffusion of the Steam Engine in Britain, 1700-1800. A Reappraisal." Cliometrica, 5, 291-321. 
O'Rourke, Kevin H., Ahmed S. Rahman, and Alan M. Taylor (2013). "Luddites, the Industrial Revolution, and the Demographic Transition." Journal of Economic Growth, 18, 373-409.

Pisati, Maurizio (2001). "sg162: Tools for Spatial Data Analysis." Stata Technical Bulletin, 60, 21-37.

Sanderson, M. (1972). "Literacy and Social Mobility in the Industrial Revolution in England." Past \& Present, 56, 75-104.

Schofield, Roger (1973). "Dimensions of Illiteracy, 1750-1850.” Explorations in Economic History, $10,437-454$.

Schofield, R. (1985). “English Marriage Patterns Revisited.” Journal of Family History, 10, 2-20.

Schools Inquiry Commission (1868a). London: Printed by GE. Eyre \& W. Spottiswoode for H. M. Stationery Office, 1868.

Schools Inquiry Commission (1868b). Vols. 2-20, edited by G. E. Eyre and W. Spottiswoode.

Shaw-Taylor, Leigh, Peter M. Kitson, and E. A. Wrigley (2006). "1813-20 Parish Register Occupational Data for England and Wales." These datasets were made possible through two grants from the ESRC: The changing occupational structure of nineteenth century Britain (RES000-23-1579) and ESRC: Male occupational change and economic growth in England 1750-1851 (RES 000-23-0131).

Squicciarini, Mara P. and Nico Voigtländer (2015). "Human Capital and Industrialization: Evidence from the Age of Enlightenment.” The Quarterly Journal of Economics, 130, 1825-1883.

Stephens, William B. (1987). Education, Literacy and Society, 1830-70: The Geography of Diversity in Provincial England. Manchester University Press.

van der Beek, Karine (2014). "England's Eighteenth-Century Demand for High-Quality Workmanship: Evidence from Apprenticeship, 1710-1770." In Institutions, Innovation, and Industrialization: Essays in Economic History and Development, a Festschrift Volume in the Honor of Prof. Joel Mokyr, edited by Avner Greif, Lynne Kiesling, and John V. C. Nye. Princeton University Press.

van Leeuwen, Marco H. D. and Ineke Maas (2011). HISCLASS: A Historical International Social Class Scheme. Leuven University Press.

van Zanden, Jan Luiten (2009). "The Skill Premium and the 'Great Divergence'." European Review of Economic History, 13, 121-153.

von Tunzelmann, Nick (1978). Steam Power and British Industrialization to 1860. Clarendon Press. von Tunzelmann, Nick (1986). "Coal and Steam Power." In Atlas of Industrializing Britain, edited by John Langton and R. J. Morris. London: Muthuen.

Wrigley, E. A. (2007). "English County Populations in the Later Eighteenth Century." Economic History Review, 60, 35-69.

Wrigley, E. A. (2010). Energy and the English Industrial Revolution. Cambridge University Press.

Wrigley, E. A. (2016). The Path to Sustained Growth. England's Transition from an Organic Economy to an Industrial Revolution. Cambridge University Press.

Zeev, Nadav B., Joel Mokyr, and Karine van der Beek (2017). "Flexible Supply of Apprenticeship in the British Industrial Revolution." Journal of Economics History, 77, 208-250.

\section{Supplementary Data}

Supplementary data are available at JEEA online. 